CENTRE for ECONOMIC

$P$ E R F O R M A N C E

CEP Discussion Paper No 699

July 2005

\title{
Products and Productivity
}

\author{
Andrew B. Bernard, Stephen Redding \\ and Peter K. Schott
}

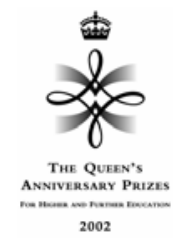




\begin{abstract}
Firms' decisions about which goods to produce are often made at a more disaggregate level than the data observed by empirical researchers. When products differ according to production technique or the way in which they enter demand, this data aggregation problem introduces a bias into standard measures of firm productivity. We develop a theoretical model of heterogeneous firms endogenously self-selecting into heterogeneous products. We characterize the bias introduced by unobserved variation in product mix across firms, and the implications of this bias for identifying firm and industry responses to exogenous policy shocks such as deregulation. More generally, we demonstrate that product switching gives rise to a richer set of industry-level dynamics than models where firm product mix remains fixed.
\end{abstract}

Keywords: Product choice, Productivity, Deregulation, Industry Evolution JEL classifications: L11, D21, L60

Keywords: Product choice, Productivity, Deregulation, Industry Evolution JEL Classifications: L11, D21, L60

This paper was produced as part of the Centre's Globalisation Programme. The Centre for Economic Performance is financed by the Economic and Social Research Council.

\title{
Acknowledgements
}

Andrew Bernard and Peter Schott acknowledge financial support from the National Science Foundation (SES-0241474). Redding acknowledges financial support from a Philip Leverhulme Prize. Responsibility for any opinions and errors lies with the authors.

Andrew B. Bernard is an Associate Professor of Business Administration at Tuck School of Business in the US Email: andrew.b.Bernard@dartmouth.edu. Stephen Redding is a member of the Centre for Economic Performance and a lecturer in Economics at the London School of Economics. Email: s.j.redding@1se.ac.uk. Peter K. Schott is an Assistant Professor of Economics at Yale School of Management. Email: peter.schott@yale.edu.

Published by

Centre for Economic Performance

London School of Economics and Political Science

Houghton Street

London WC2A $2 \mathrm{AE}$

All rights reserved. No part of this publication may be reproduced, stored in a retrieval system or transmitted in any form or by any means without the prior permission in writing of the publisher nor be issued to the public or circulated in any form other than that in which it is published.

Requests for permission to reproduce any article or part of the Working Paper should be sent to the editor at the above address.

(C) A. B. Bernard, S. Redding and P. K. Schott, submitted 2005

ISBN 0753018799 


\section{Introduction}

Product choice is one of the central business decisions made by a firm. Apple's decision to enter the market for personal music players with the iPod was a substantive departure from its existing product mix and has received much attention. ${ }^{1}$ While central to business strategy, firms' decisions about which product markets to enter are often made at a more disaggregate level than the data available to researchers. This mismatch is important for the measurement of productivity because the products that firms switch into may utilize different production techniques - and display different consumer demand patterns - than the products firms leave behind. As a result, variation in firms' observed performance may be driven by unobserved product choices in addition to underlying (and observable) firm characteristics.

This paper examines the implications of unobserved product-mix variation and product switching for the measurement of firm- and industry-level productivity. We develop a general equilibrium model of industry evolution where heterogeneous firms endogenously self-select into asymmetric products within an industry. We demonstrate that production-technology differences across products and product-choice variation across firms interact to bias standard superlative-index and production-functionbased estimates of firm productivity. This bias persists even if the econometrician can observe and control for firm-specific variation in prices, inputs and output. Solving the problem requires knowledge of the evolution of firms' product mix over time.

We demonstrate that measured productivity differences across firms can be decomposed into a component due to true differences in firm productivity and a component attributable to variation in production technology across products. Depending on how product technologies vary, measured productivity dispersion can exceed or fall short of true productivity variation. This finding suggests that differences in firms' product mix may play a role in explaining the substantial within-industry variation in firm productivity noted in many empirical studies. ${ }^{2}$ At the industry level, we show that measured productivity depends upon the weight of products in consumer utility. Changes in these weights cause estimated productivity to rise or fall even if true industry productivity remains the same.

Our approach emphasizes the role of product choice by surviving firms - along with ongoing entry and exit of firms - in mediating firm and industry responses to exogenous shifts in public policy such as deregulation. We show that estimates of

\footnotetext{
${ }^{1}$ See, for example, 'The Meaning of iPod', The Economist, June 10th, 2004.

${ }^{2}$ See, for example, the survey in Foster et al. (2001).
} 
these responses are biased in the presence of unobserved product switching. Even though true firm productivity is a parameter in the model and remains unchanged during deregulation, firms may appear as if they are experiencing productivity growth due to their endogenous decisions to switch products. For this reason, identification of firm productivity growth as a result of policy reforms is incomplete unless information on the goods firms produce before and after the reform is incorporated into the analysis. More generally, we demonstrate that product switching gives rise to a richer set of industry-level dynamics than models where firm product mix remains fixed. In the framework we develop, deregulation generates aggregate (i.e., industrylevel) productivity growth through three channels: the exit of low productivity firms, changes in the composition of output across firms that keep making the same product, and changes in the relative importance of different product markets within the same industry. Accounting for these responses promotes more comprehensive evaluations of public policy.

Our findings contribute to a wide range of research in the international trade, productivity and macroeconomic growth literatures. A great deal of empirical work in these fields has made use of plant- and firm-level datasets from production censuses or surveys. These micro datasets have yielded many insights and are a considerable improvement over the industry-level datasets that preceded them. ${ }^{3}$ Nevertheless, most studies making use of microdata assign firms (or plants) to a single, relativelyaggregate industry despite variation in firms' underlying product mix. ${ }^{4}$ In the U.S. manufacturing census, for example, BMW would be allocated to the four-digit Standard Industry Classification (SIC) 3711 "Motor Vehicles and Car Bodies" based on the company's main source of revenue, which is manufacturing passenger cars. But passenger cars are only one five-digit product within this four-digit industry. Firms producing buses, combat vehicles, tractors and a variety of truck categories would also be found in SIC 3711. ${ }^{5}$ As a result, estimation of BMW's productivity might involve

\footnotetext{
${ }^{3}$ Early studies using microdata include Davis and Haltiwanger (1991) and Baily et al. (1992).

${ }^{4}$ Exceptions are where detailed information on the product market is used, as for example in Berry et al. (1995), Goldberg (1995) and Syverson (2004).

${ }^{5}$ Similarly, the UK four-digit industry called Manufacture of Motor Vehicles (UKSIC03 3410) includes passenger cars, buses, commercial vehicle and golf carts among others. See http://www.statistics.gov.uk/methods_quality/sic/downloads/UK_SIC_Vol1(2003).pdf. Since the UK system is designed to comply with Eurostat regulations on the common statistical classification of economic activities (NACE), other European classification schemes face similar problems of clustering dissimilar products within an industry. While attempts have been made to revise industrial classifications to group products and industries by production processes, it remains inevitable that activities with heterogeneous production techniques and demand-side characteristics are classified together.
} 
grouping it with defense contractors such as AM General which produces armorplated Humvees. The likely dissimilarity of production technologies and demand patterns across products as diverse as passenger cars and combat vehicles highlights the difficulties of using coarse industry classifications to identify firm productivity.

There is a long tradition in the industrial organization literature of analyzing endogenous product choice, including Hotelling (1929), Lancaster (1966), Shaked and Sutton (1982), Spence (1976) and Sutton (1998) among others. More recent research by Berry et al. (1995), Hausman (1997), Petrin (2002) and Trajtenberg (1989) has sought to quantify the welfare gains from new product introduction. Other work has emphasized problems of measuring productivity using revenue data when firms operate in imperfectly competitive markets and charge different prices, including Klette and Griliches (1996), Levinsohn and Melitz (2002), Katayama, Lu and Tybout (2003), De Loecker (2005) and Martin (2005).

A separate tradition has analyzed industry dynamics, where the Darwinian selection of high productivity firms through entry and exit is central in determining industry equilibrium, as in Jovanovic (1982), Hopenhayn (1992) and Ericsson and Pakes (1995). In contrast with the research noted above, product choice does not feature prominently in this literature, where the decision to create a firm is equivalent to the decision to enter a product market. One explanation for this difference may be that models of industry dynamics solve for heterogeneous quantities and prices across firms and trace the stochastic evolution of the firm productivity distribution. Analyzing the dynamics of entire distributions in general equilibrium is a demanding exercise. To allow heterogeneous firms to choose between products with diverse attributes would be to introduce a further equilibrium distribution (the distribution of products across firms) that must be analyzed over time.

We make progress in this direction by adopting a number of stark assumptions. In particular, we build on Melitz's (2003) model of industry equilibrium, which substantially simplifies industry dynamics by assuming a monopolistically competitive industry structure where firms produce varieties of a single product, and by assuming that firm productivity is a parameter which is drawn from a fixed distribution at the point of entry, with firms facing a constant exogenous probability of death thereafter. Into this structure we introduce a choice between two heterogeneous products with different production techniques. These products enter demand asymmetrically, and their relative price is determined endogenously in general equilibrium. We believe this to be the simplest framework for understanding the impact of product choice on productivity measurement. It captures both product heterogeneity and self-selection 
by firms into product markets while yielding particularly tractable results.

The remainder of the paper is structured as follows. Section 2 places the paper in the context of the existing literature on deregulation, industry dynamics and productivity. Section 3 develops the theoretical model. Section 4 solves for industry equilibrium. Section 5 examines the properties of general equilibrium and derives the bias in standard productivity measures. Section 6 examines the implications of an exogenous policy reform, in the form of a reduction in barriers to entry, on product choice, measured productivity growth at the firm-level and on aggregate industry productivity growth. Section 7 concludes. An appendix at the end of the paper collects together proofs and technical derivations.

\section{Deregulation, Industry Dynamics and Productivity}

A great deal of recent research in industrial organization and international trade focuses on industry responses to deregulation and trade liberalization. The influential study of the U.S. telecommunications industry by Olley and Pakes (1996) and the analyses of trade liberalization in Chile by Tybout et al. (1991) and Pavcnik (2002) are prominent examples. An important contribution of this analysis is the development of methodologies for consistent estimation of productivity when firms endogenously choose factor inputs as well as whether or not to exit the industry in response to changing market conditions and technology. ${ }^{6}$ The estimated values of productivity that emerge from this literature show considerable dispersion across plants and firms within narrowly defined industries as well as exit by low productivity firms. Changes in the composition of output are found to play an important role in the response of industries to exogenous changes in the policy environment. Pavcnik (2002), for example, finds that aggregate productivity growth in Chile grew by 19.3 percent during the seven years following trade liberalization in 1979, with a contribution of 6.6 percent from increased productivity within plants and a 12.7 percent from the reallocation of resources from less to more efficient producers.

A related literature has argued that gross rates of firm entry and exit are large relative to net rates, and that firm entry and exit play an important role in accounting for aggregate productivity growth. Leading examples include Baily et al. (1992), Davis and Haltiwanger (1991), Dunne et al. (1989), Disney et al. (2003) and Foster et al. (2002). Foster et al. (2002), for example, find that virtually all of the productivity growth in the U.S. retail trade sector during the 1990s is accounted for by more

\footnotetext{
${ }^{6}$ See in particular Olley and Pakes (1996) and Levinsohn and Petrin (2003).
} 
productive entrants displacing less productive exiters.

Finally, a separate body of research has emphasized the problems associated with measuring productivity using revenue data when there is dispersion in output prices across firms within industries, including work by Klette and Griliches (1996), Levinsohn and Melitz (2002), Katayama et al. (2003), De Loecker (2005), and Martin (2005). In the presence of this price dispersion, deflating firm revenue using a common industry price deflator, as is common in empirical work, yields biased estimates of firm productivity.

The theoretical model we develop in this paper incorporates all of these features: heterogeneous firm productivity, ongoing entry and exit in steady-state, selection on survival where exiting firms are on average of lower productivity, and imperfect competition inducing variation in prices across firms. In addition, we incorporate an additional feature of firm-level data not emphasized in existing research, namely the idea that firm choices about which good to manufacture are typically made at a more disaggregate level than the industry concordances according to which firms are classified. These products often have different production technologies and display heterogeneous consumer demand patterns, which mean that they are not well modelled as differentiated varieties of the same product. Even if firm-specific data on prices or information on physical quantities of output is available, measured firm productivity is biased because it captures both true productivity differences across firms as well as differences across products in production technique.

We illustrate the importance of these ideas by describing a particular micro dataset, the Longitudinal Research Database (LRD) of the U.S. Census Bureau. In the LRD, manufacturing censuses are conducted every five years. Plants are allocated to four-digit SIC industries, of which there are 457, according to the industry that accounts for the main share of plant revenue. Information on output and inputs such as employment, wages, physical capital, materials, and energy is reported at the plant-level.

Existing research relying on the LRD generally focuses on plants' primary industries. $^{7}$ However, more detailed information on plant production is available. The LRD also tracks the identity and output of plants' five-digit SIC products, of which there are 1462. To provide a sense of the relative level of detail between products and industries, Table 1 lists the thirteen products captured by industry 3357, "Nonferrous Wire-Drawing and Insulating." The products in this industry - which range from Copper Wire (33571) to Fiber Optic Cable (33579) - differ both in terms of end

\footnotetext{
${ }^{7}$ See, for example, Baily et al. (1992), Davis and Haltiwanger (1991) and Olley and Pakes (1996).
} 
use and in terms of the inputs and technologies required to manufacture them. The current UK SIC2003 system also groups fiber optic and insulated wire cable under the four-digit industry 3130, Manufacture of Insulated Wire and Cable. ${ }^{8}$

Table 2 provides a more systematic view of the level of product detail available in the U.S. SIC by reporting the number of four- and five-digit categories in each two-digit sector. The typical two-digit manufacturing sector has 24 industries and 76 products. However, there is a substantial degree of variation across sectors. The number of five-digit products per two-digit sector ranges from a low of 12 in Leather (31) to 187 in Industrial Machinery (35). Similarly, the number of five-digit products per four-digit industry ranges from a low of 1.1 in Leather to a high of 5.1 in Printing and Publishing (27). The industry highlighted in Table 1, Nonferrous Wiredrawing and Insulating (3357), is just one of 26 Primary Metal industries, and its products represent 14 percent $(13 / 89)$ of the total number of products in that sector.

In the theoretical model developed below, we allow heterogeneous firms to endogenously self-select into products that vary in terms of their demand and supply-side attributes. Product choice is shaped by the interaction of the heterogeneous characteristics of firms and products. The product chosen by the firm affects its measured productivity and its response to industry deregulation. The distribution of firms across products influences measured industry productivity at a point in time. The endogenous re-sorting of firms across products in response to industry deregulation shapes the dynamic response of the industry as a whole to policy reform over time.

\section{Theoretical Model}

Consider a single industry within which consumers and firms choose whether to consume and produce varieties of two distinct products. ${ }^{9}$ To keep the analysis as tractable as possible, we assume that consumer preferences between the two products

\footnotetext{
${ }^{8}$ Even at further levels of disaggregation, e.g. seven-digit SIC categories, goods are often quite distinct. For example, in the Motor Vehicles Parts and Accessories industry (3714), the five-digit product "Gasoline Engines and Gasoline Engine Parts for Motor Vehicles, New" (37142) includes the following seven-digit categories: "Intake Manifolds" (3714206), "Rocker Arms and Parts (3714215), "Fuel Injection Systems" (3714218), and "Radiators, Complete" (3714235). These seven-digit categories are likely to display heterogeneous technological requirements and to face different patterns of consumer demand. For a complete list of four-, five-, and seven- digit SIC87 categories, see U.S. Census (1996) available at http://www.census.gov/prod/2/manmin/mc92-r-1.pdf.

${ }^{9}$ It is straightforward to embed this framework in a multi-industry model or to allow a finite number of distinct products within the industry. The model developed here is the simplest framework within which to demonstrate the importance of firms' choice between heterogeneous products in influencing measured firm and industry outcomes.
} 
can be well represented with the following CES utility function:

$$
U=\left[a C_{1}^{\nu}+(1-a) C_{2}^{\nu}\right]^{1 / \nu} .
$$

where $a$ captures the relative strength of preferences for each product, and we assume that the products are imperfect substitutes with elasticity of substitution $\psi=\frac{1}{1-\nu}>$ 1. Firms produce horizontally differentiated varieties of their chosen product. $C_{i}$ is therefore a consumption index defined over varieties $\omega$ of each product $i$ :

$$
C_{i}=\left[\int_{\omega \in \Omega_{i}} q_{i}(\omega)^{\rho} d \omega\right]^{1 / \rho}, \quad P_{i}=\left[\int_{\omega \in \Omega_{i}} p_{i}(\omega)^{1-\sigma} d \omega\right]^{1 / 1-\sigma} .
$$

where $\left\{\Omega_{i}\right\}$ is the set of available varieties in market $i, P_{i}$ is the price index dual to $C_{i}$, and $\sigma=\frac{1}{1-\rho}>1$ is the elasticity of substitution between varieties of the same product. We make the natural assumption that varieties of the same product are more easily substitutable than different products, so that $\sigma>\psi$.

Consumer expenditure minimization yields the following expression for equilibrium expenditure (equals revenue, $r_{i}(\omega)$ ) on a variety:

$$
r_{i}(\omega)=R_{i}\left(\frac{p_{i}(\omega)}{P_{i}}\right)^{1-\sigma}=\alpha_{i}(\mathcal{P}) R\left(\frac{p_{i}(\omega)}{P_{i}}\right)^{1-\sigma}
$$

which is increasing in aggregate expenditure (equals aggregate revenue $R=R_{1}+R_{2}=$ $\left.\int_{\omega \in \Omega_{1}} r_{1}(\omega) d \omega+\int_{\omega \in \Omega_{2}} r_{2}(\omega) d \omega\right)$, increasing in the share of expenditure allocated to product $i, \alpha_{i}\left(P_{2} / P_{1}\right)=\alpha_{i}(\mathcal{P})$, decreasing in own variety price, $p_{i}(\omega)$, and increasing in the price of competing varieties as summarized in the price index, $P_{i}$.

With CES utility, the share of expenditure allocated to product 1 is increasing in the relative price of product $2, \mathcal{P}=P_{2} / P_{1}$ (since $\psi>1$ ), and increasing in the relative weight given to product 1 in consumer utility, $a$ :

$$
\alpha_{1}(\mathcal{P})=\left[1+\left(\frac{1-a}{a}\right)^{\psi} \mathcal{P}^{1-\psi}\right]^{-1}, \quad \alpha_{2}(\mathcal{P})=1-\alpha_{1}(\mathcal{P})
$$

\subsection{Production}

As well as entering demand in different ways, the products have different production technologies. We consider the case where this difference in production technology takes the form of a difference in the fixed and variable costs of production. We assume that product 2 has a higher fixed cost of production: $f_{2}>f_{1}$. Variable costs are indexed by the parameter $b_{i}$ and, without loss of generality, we normalize $b_{1}=1$ 
and $b_{2}=b$. We allow variable costs of production for product 2 to be either smaller or greater than those for product 1.

Labor is the sole factor of production and is supplied inelastically at its aggregate level $L$, which also indexes the size of the economy. The production technology follows Melitz (2003) in that variable cost is assumed to depend on heterogeneous firm productivity. We differ in that we allow for multiple distinct products and hence endogenous product choice within the industry. The labor required to produce $q_{i}$ units of a variety in product market $i$ is given by:

$$
l_{i}=f_{i}+\frac{b_{i} q_{i}}{\varphi}
$$

so that the variable cost of production depends on $b_{i}$, which is common to all firms, as well as on the firm-specific productivity, $\varphi .{ }^{10}$

The existence of fixed production costs implies that, in equilibrium, each firm will choose to produce a unique variety. Profit maximization yields the standard result that equilibrium prices are a constant mark-up over marginal cost, with the size of the mark-up depending on the elasticity of substitution between varieties:

$$
p_{i}(\varphi)=\left(\frac{\sigma}{\sigma-1}\right) \frac{w b_{i}}{\varphi} .
$$

We choose the wage as the numeraire so that $w=1$. Using this choice of numeraire and the pricing rule in the expression for revenue above, equilibrium firm revenue and profits are:

$$
\begin{aligned}
r_{i}(\varphi) & =\alpha_{i}(\mathcal{P}) R\left(P_{i} \rho \frac{\varphi}{b_{i}}\right)^{\sigma-1} \\
\pi_{i}(\varphi) & =\frac{r_{i}(\varphi)}{\sigma}-f_{i} .
\end{aligned}
$$

One property of equilibrium revenue that will prove useful below is that the relative revenue of two firms with different productivity levels in the same product market depends solely on their relative productivity: $r_{i}\left(\varphi^{\prime \prime}\right)=\left(\varphi^{\prime \prime} / \varphi^{\prime}\right)^{\sigma-1} r_{i}\left(\varphi^{\prime}\right)$. Similarly, the relative revenue of two firms with different productivity levels in different product markets depends on their relative productivities, the relative variable cost of making

\footnotetext{
${ }^{10}$ The assumption that fixed costs of production are independent of productivity captures the idea that many fixed costs, such as building and equipping a factory with machinery, are unlikely to vary substantially with firm productivity. As long as fixed costs are less sensitive to productivity than variable costs, there will be endogenous selection on productivity in firms' exit and product choice decisions.
} 
the two products, the relative expenditure share devoted to the two products, and relative price indices:

$$
r_{2}\left(\varphi^{\prime \prime}\right)=\left(\frac{1-\alpha_{1}(\mathcal{P})}{\alpha_{1}(\mathcal{P})}\right)\left[\left(\frac{\varphi^{\prime \prime}}{\varphi^{\prime}}\right) \mathcal{P} \frac{1}{b}\right]^{\sigma-1} r_{1}\left(\varphi^{\prime}\right)
$$

\subsection{Industry Entry and Exit}

To enter the industry (and produce either product), firms must pay a fixed entry cost, $f_{e}>0$, which is thereafter sunk. After paying the sunk cost, firms draw their productivity, $\varphi$, from a distribution, $g(\varphi)$, with corresponding cumulative distribution $G(\varphi)$. This formulation captures the idea that there are sunk costs of entering an industry and that, once these costs are incurred, some uncertainty regarding the nature of production and firm profitability is realized. Firm productivity is assumed to remain fixed thereafter, and firms face a constant exogenous probability of death, $\delta$, which we interpret as due to force majeure events beyond managers' control. ${ }^{11}$

A particularly tractable productivity distribution, which we use at some points below and which provides a good approximation to observed firm-level productivity data is the Pareto distribution, $g(\varphi)=z k^{z} \varphi^{-(z+1)}$. The parameter $k>0$ corresponds to the minimum value of productivity in the industry, while $z>0$ determines the skewness of the distribution, and in order for the variance of log firm sales to be finite we require $z>\sigma-1$.

After entry, firms decide whether to begin producing in the industry or exit. If they decide to produce, they choose which product to make. The value of a firm with productivity $\varphi$ is, therefore, the maximum of 0 (if the firm exits) or the stream of future profits from producing one of the two products discounted by the probability of firm death:

$$
v(\varphi)=\max \left\{0, \frac{1}{\delta} \pi_{1}(\varphi), \frac{1}{\delta} \pi_{2}(\varphi)\right\} .
$$

\footnotetext{
${ }^{11}$ Firm death ensures steady-state entry into the industry. New entrants make an endogenous exit decision, since their decision whether or not to produce in the industry depends on their productivity draw $\varphi$ from the distribution $g(\varphi)$. Together with fixed production costs, this will generate the result that exiting firms are on average less productive than surviving firms. For incumbent firms, the probability of death $\delta$ is independent of productivity. This assumption can be relaxed by allowing firm productivity to evolve stochastically after entry (e.g. Hopenhayn 1992). While this would achieve greater realism, it would not change the qualitative results below on the importance of endogenous product choice for measured firm and industry productivity, and would come at the cost of a substantial increase in the complexity of the industry dynamics.
} 


\subsection{Product Choice}

Firms decide which product to make based on their realized productivity, taking as given aggregate variables such as the price indices. From our expression for equilibrium profits above, firms with zero productivity have negative post-entry profits and profits are monotonically increasing in productivity. Fixed production costs mean that there is a positive value for productivity below which negative profits would be made. Firms drawing a productivity below this zero-profit productivity cutoff, $\varphi^{*}$, exit the industry immediately.

From consumers' utility function, the elasticity of substitution between products is lower than the elasticity of substitution between varieties of the same product. Therefore, in general equilibrium the relative price of the two products, $\mathcal{P}=P_{2} / P_{1}$, adjusts so as to ensure that both products are produced, as we show formally below.

Since product 2 has a higher fixed product cost than product 1 , firms with zero productivity would make the largest losses from producing product 2 :

$$
0>\pi_{1}(0)=-f_{1}>\pi_{2}(0)=-f_{2} .
$$

Since profits for each product are monotonically increasing in productivity, a necessary condition for both products to be produced is that profits from product 2 increase more rapidly with productivity than those from product 1 :

$$
\frac{d \pi_{2} / d \varphi}{d \pi_{1} / d \varphi}=\Gamma \equiv\left(\frac{1-a}{a}\right)^{\psi}\left(\frac{1}{b}\right)^{\sigma-1} \mathcal{P}^{\sigma-\psi}>1
$$

where the relative rate at which profits increase with productivity is independent of productivity, and depends instead on parameters, such as the demand-shifter $a$ and the variable cost parameter $b$, as well as endogenous relative price indices, $\mathcal{P}$.

The sufficient condition for both products to be produced is that profits are positive in each product market and exceed those in the other product market over a range of productivities:

$$
\begin{aligned}
& \pi_{1}(\varphi)>0 \text { and } \pi_{1}(\varphi)>\pi_{2}(\varphi) \text { for } \varphi \in \Phi_{1} \subset(0, \infty) \\
& \pi_{2}(\varphi)>0 \text { and } \pi_{2}(\varphi)>\pi_{1}(\varphi) \text { for } \varphi \in \Phi_{2} \subset(0, \infty)
\end{aligned}
$$

which requires the profit functions for the two products to intersect at a value for productivity where positive profits are made, as shown graphically in Figure 1. As we show formally below, endogenous relative prices, $\mathcal{P}$, will adjust to ensure that these conditions are satisfied even if product 2 has both a higher fixed and variable 
cost. The point at which the two profit functions intersect defines the productindifference productivity cutoff, $\varphi^{* *}$, at which a firm is exactly indifferent between the two products.

The higher fixed cost for product 2 and the requirement that the two profit functions intersect at a value for productivity where positive profits are made together imply that product 1 will be produced by the lowest productivity firms that are active in the industry and product 2 will be produced by higher productivity firms. The zero-profit productivity cutoff determining the lowest level of productivity where product 1 is produced is given by:

$$
r_{1}\left(\varphi^{*}\right)=\sigma f_{1},
$$

while the product-indifference productivity cutoff defining the lowest level of productivity where product 2 is produced is defined by:

$$
\frac{r_{2}\left(\varphi^{* *}\right)}{\sigma}-f_{2}=\frac{r_{1}\left(\varphi^{* *}\right)}{\sigma}-f_{1} .
$$

Firms drawing a productivity below $\varphi^{* *}$ but above $\varphi^{*}$ will make product 1 , while those drawing a productivity above $\varphi^{* *}$ will make product 2 .

\subsection{Free Entry}

From the characterization of entry and product choice in the previous sections, the ex ante probability of successful entry into the industry is $\left[1-G\left(\varphi^{*}\right)\right]$, with the $e x$ ante probability of producing product 1 given by $\left[G\left(\varphi^{* *}\right)-G\left(\varphi^{*}\right)\right]$, and the ex ante probability of producing product 2 given by $\left[1-G\left(\varphi^{* *}\right)\right]$. The ex post productivity distribution for each product, $\mu_{i}(\varphi)$, is conditional on successful entry and product choice and is a truncation of the ex ante productivity distribution, $g(\varphi)$ :

$$
\begin{aligned}
& \mu_{1}(\varphi)=\left\{\begin{array}{cc}
\frac{g(\varphi)}{G\left(\varphi^{* *}\right)-G\left(\varphi^{*}\right)} & \text { if } \varphi \in\left[\varphi^{*}, \varphi^{* *}\right) \\
0 & \text { otherwise }
\end{array}\right. \\
& \mu_{2}(\varphi)=\left\{\begin{array}{cc}
\frac{g(\varphi)}{1-G\left(\varphi^{* *}\right)} & \text { if } \varphi \in\left[\varphi^{* *}, \infty\right) \\
0 & \text { otherwise }
\end{array}\right.
\end{aligned}
$$

In equilibrium we require the expected value of entry in the industry, $v_{e}$, to equal the sunk entry cost, $f_{e}$. The expected value of entry is the ex ante probability of making product 1 times expected profitability in product 1 until death plus the $e x$ 
ante probability of making product 2 times expected profitability in product 2 until death, and the free entry condition is:

$$
v_{e}=\left[\frac{G\left(\varphi^{* *}\right)-G\left(\varphi^{*}\right)}{\delta}\right] \bar{\pi}_{1}+\left[\frac{1-G\left(\varphi^{* *}\right)}{\delta}\right] \bar{\pi}_{2}=f_{e},
$$

where $\bar{\pi}_{i}$ is expected or average firm profitability in product market $i$. Equilibrium revenue and profit in each market are constant elasticity functions of firm productivity (equation (7)) and, therefore, average revenue and profit are equal respectively to the revenue and profit of a firm with weighted average productivity, $\bar{r}_{i}=r_{i}\left(\widetilde{\varphi}_{i}\right)$ and $\bar{\pi}_{i}=\pi_{i}\left(\widetilde{\varphi}_{i}\right)$, where weighted average productivity, $\tilde{\varphi}_{1}\left(\varphi^{*}, \varphi^{* *}\right)$ and $\tilde{\varphi}_{2}\left(\varphi^{* *}\right)$, is determined by the ex post productivity distributions, $\mu_{i}(\varphi)$, and is defined formally in the Appendix.

\subsection{Product and Labor Markets}

The steady-state equilibrium is characterized by a constant mass of firms entering each period, $M_{e}$, and a constant mass of firms producing within each product market, $M_{i}$. In steady-state equilibrium, the mass of firms that enter and draw a productivity sufficiently high to produce in a product market must equal the mass of firms already within that product market who die, yielding the following steady-state stability conditions (SC):

$$
\begin{aligned}
{\left[1-G\left(\varphi^{* *}\right)\right] M_{e} } & =\delta M_{2} \\
{\left[G\left(\varphi^{* *}\right)-G\left(\varphi^{*}\right)\right] M_{e} } & =\delta M_{1} .
\end{aligned}
$$

The firms' equilibrium pricing rule implies that the prices charged for individual varieties are inversely related to firm productivity. The price indices are weighted averages of the prices charged by firms with different productivities, with the weights determined by the ex post productivity distributions. Exploiting this property of the price indices, we can write them as functions of the mass of firms producing a product, $M_{i}$, and the price charged by a firm with weighted average productivity within each product market, $p_{i}\left(\widetilde{\varphi}_{i}\right)$ :

$$
P_{1}=M_{1}^{1 / 1-\sigma} p_{1}\left(\widetilde{\varphi}_{1}\right), \quad P_{2}=M_{2}^{1 / 1-\sigma} p_{2}\left(\widetilde{\varphi}_{2}\right)
$$

In equilibrium, we also require that the demand for labor used in production, $L^{p}$, and entry, $L^{e}$, equals the economy's supply of labor, $L$ :

$$
L_{p}+L_{e}=L
$$




\section{Industry Equilibrium}

In this section, we characterize general equilibrium which is referenced by the sextuple $\left\{\varphi^{*}, \varphi^{* *}, P_{1}, P_{2}, R_{1}, R_{2}\right\}$, in terms of which all other endogenous variables may be written. In the next section we analyze the properties of industry equilibrium and the implications of product choice for measured firm and industry productivity. In the following section we investigate the implications of industry deregulation, in the form of a policy reform which reduces sunk costs of entry into the industry.

The equilibrium vector is determined by the following equilibrium conditions: the zero-profit productivity cutoff (equation (13)), the product-indifference productivity cutoff (equation (14)), free entry (16), steady-state stability ((17) and (18)), the values for the equilibrium price indices implied by consumer and producer equilibrium (equation (19)), and labor market clearing (20).

\subsection{Relative Supply and Relative Prices}

The zero-profit productivity cutoff implies that the revenue of a product 1 firm with productivity $\varphi^{*}$ is proportional to the product 1 fixed production cost (equation (13)), while the product-indifference productivity cutoff establishes a relationship between relative revenue in the two markets at productivity $\varphi^{* *}$ and the fixed costs of producing the two products (equation (14)). Profit maximization implies that the relative revenues of two firms making different products depend solely on their relative productivities, relative expenditure shares on the two products, relative price indices, and relative variable costs of production (equation (8)).

Combining these three equations, we obtain a downward-sloping (supply-side) relationship between two key variables: the relative value of the two productivity cutoffs, $\varphi^{* *} / \varphi^{*}$, and the relative price of the two products, $\mathcal{P}$,

$$
\frac{\varphi^{* *}}{\varphi^{*}} \equiv \Lambda=\left[\frac{\left(\frac{f_{2}}{f_{1}}-1\right)}{\left[\left(\frac{1-a}{a}\right)^{\psi}\left(\frac{1}{b}\right)^{\sigma-1} \mathcal{P}^{\sigma-\psi}-1\right]}\right]^{1 /(\sigma-1)} .
$$

Equation (21) is the mathematical statement of the relationship between the two productivity cutoffs captured graphically in Figure 1 . As $\varphi^{* *}$ rises relative to $\varphi^{*}$, the fraction of firms producing product 2 falls, and the fraction of firms producing product 1 increases. Equation (21) therefore yields the following intuitive comparative statics. A higher value for the relative price, $\mathcal{P}$, increases profitability in product 2 relative to product 1 and causes the relative number of firms producing product 2 to rise, 
i.e. a reduction in $\varphi^{* *}$ relative to $\varphi^{*}$, since $\sigma>\psi$. For a given value for the relative price, $\mathcal{P}$, a higher fixed cost for product $2, f_{2}$, reduces profitability in product 2 and causes the relative number of firms producing product 2 to fall, i.e. an increase in $\varphi^{* *}$ relative to $\varphi^{*}$.

\subsection{Relative Demand and Relative Prices}

The expressions for the two price indices yield an equation for relative prices as a function of the relative mass of firms and the relative price charged by a firm with weighted average productivity in each product market (equation (19)). The two steady-state stability conditions yield an equation for the relative mass of firms as a function of the two productivity cutoffs (equations (17) and (18)).

Combining these expressions yields an upward-sloping demand-side relationship between the relative value of the two productivity cutoffs and the relative price of the two products:

$$
\Psi\left(\frac{\varphi^{* *}}{\varphi^{*}}\right) \equiv\left[\frac{b^{\sigma-1} \int_{\varphi^{*}}^{\varphi^{* *}} \varphi^{\sigma-1} g(\varphi) d \varphi}{\int_{\varphi^{* *}}^{\infty} \varphi^{\sigma-1} g(\varphi) d \varphi}\right]=\mathcal{P}^{\sigma-1} .
$$

An increase in the relative consumer price index for product $2, \mathcal{P}$, reduces demand for product 2 relative to product 1 and shrinks the range of productivities where product 2 is produced relative to the range where product 1 is produced, i.e. an increase in $\varphi^{* *} / \varphi^{*}$. For a given value of $\varphi^{* *} / \varphi^{*}$, an increase in $b$, the relative variable cost for product 2 , raises the price of product 2 varieties relative to product 1 varieties, i.e. an increase in $\mathcal{P}$.

\subsection{Free Entry}

The free entry condition can be written in a more convenient form using the expression for the zero-profit productivity cutoff, the relationship between the revenues of firms producing varieties in the same market with different productivities, and the supply-side relationship between the two productivity cutoffs derived above. Combining equation (13), $r_{i}\left(\varphi^{\prime \prime}\right)=\left(\varphi^{\prime \prime} / \varphi^{\prime}\right)^{\sigma-1} r_{i}\left(\varphi^{\prime}\right)$, and equation (21), we can write the free entry condition as: 


$$
\begin{aligned}
v_{e}= & \frac{f_{1}}{\delta} \int_{\varphi^{*}}^{\Lambda \varphi^{*}}\left[\left(\frac{\varphi}{\varphi^{*}}\right)^{\sigma-1}-1\right] g(\varphi) d \varphi \\
& +\frac{f_{1}}{\delta} \int_{\Lambda \varphi^{*}}^{\infty}\left[\left(\frac{1-a}{a}\right)^{\psi}\left(\frac{1}{b}\right)^{\sigma-1} \mathcal{P}^{\sigma-\psi}\left(\frac{\varphi}{\varphi^{*}}\right)^{\sigma-1}-\frac{f_{2}}{f_{1}}\right] g(\varphi) d \varphi=f_{e} .
\end{aligned}
$$

where $\Lambda$ is defined in equation (21).

This way of writing the free entry condition clarifies the relationship between the sunk cost of entry and the zero-profit productivity cutoff. An increase in the sunk entry cost, $f_{e}$, requires an increase in the expected value of entry, $v_{e}$. Since the expected value of entry above is monotonically decreasing in $\varphi^{*}$, this requires a fall in the zero-profit productivity cutoff. Intuitively, the higher sunk cost of entering the industry reduces the mass of entrants, which increases ex post profitability, enabling lower productivity firms to cover their fixed production costs and survive in the industry.

\subsection{Steady-state Stability, Labor Market Clearing and Goods Market Clearing}

Using the steady-state stability conditions to substitute for the ex ante probability of producing each product in the free entry condition, total payments to labor used in entry equal total industry profits: $L_{e}=M_{e} f_{e}=M_{1} \bar{\pi}_{1}+M_{2} \bar{\pi}_{2}=\Pi$ (by choice of numeraire, $w=1$ ). The existence of a competitive fringe of potential entrants means that firms enter until the expected value of entry equals the sunk entry cost, and as a result the entire value of industry profits is paid to labor used in entry.

Total payments to labor used in production equal the difference between industry revenue, $R$, and industry profits, $\Pi: L_{p}=R-\Pi$. Taking these two results together, total payments to labor used in both entry and production equal industry revenue, $L=R$. Substituting for $R$ in the expressions for $L_{e}$ and $L_{p}$ above, this establishes that the labor market clears.

In equilibrium we also require the goods market to clear, which implies that the value of expenditure equals the value of revenue for each product. Utility maximization implies that the consumer allocates the expenditure shares $\alpha_{1}(\mathcal{P})$ and $\left(1-\alpha_{1}(\mathcal{P})\right)$ to the two products. Imposing expenditure equals revenue for each product, goods market clearing may be expressed as:

$$
R_{1}=\alpha_{1}(\mathcal{P}) R, \quad R_{2}=(1-\alpha(\mathcal{P})) R
$$




\subsection{Existence and Uniqueness of Equilibrium}

Proposition 1 There exists a unique value of the equilibrium vector $\left\{\varphi^{*}, \varphi^{* *}, P_{1}\right.$, $\left.P_{2}, R_{1}, R_{2}\right\}$. All other endogenous variables of the model may be written as functions of this equilibrium vector.

Proof. See Appendix

Combining the supply-side relationship between the relative productivity cutoffs and relative prices in equation (21) with the demand-side relationship in equation (22) yields a unique equilibrium value of $\varphi^{* *} / \varphi^{*}$ and $\mathcal{P}=P_{2} / P_{1}$. In the proof of Proposition 1 , we establish that at the unique equilibrium value of $\mathcal{P}, \varphi^{*}>0$ and $\varphi^{* *}>\varphi^{*}$, so that both products are produced in equilibrium.

\section{Properties of Industry Equilibrium}

\subsection{Endogenous Selection Into Product Markets}

Proposition 2 There is non-random selection into product markets, whereby high productivity firms produce the high fixed cost product.

Proof. See Appendix.

Firms endogenously sort into products based on their heterogeneous characteristics and the diverse attributes of products. As shown in Figure 1 only higher productivity firms find it profitable to produce the higher fixed cost product. The value for productivity at which the higher fixed cost product is produced depends on the exogenous parameters of the production technology and endogenous relative prices. Because consumers have a taste for each product, and the elasticity of substitution between products is lower than between varieties of the same product, relative prices adjust so that both products are produced in equilibrium, even if one of the products has both a higher fixed and variable cost.

With a Pareto productivity distribution, the demand-side relationship between relative prices and the relative value of the productivity cutoffs in equation (22) simplifies to yield the following expression for relative prices:

$$
\mathcal{P}=b\left[\left(\varphi^{* *} / \varphi^{*}\right)^{\gamma}-1\right]^{1 / \sigma-1} .
$$


Combining this demand-side relationship with the supply-side relationship between relative prices and the two productivity cutoffs in equation (21), we obtain the following expression for the relative value of the two productivity cutoffs as a function of parameters alone:

$$
\left[\left(\frac{\varphi^{* *}}{\varphi^{*}}\right)^{\gamma}-1\right]^{\frac{1}{\sigma-1}}=\left[\left(\frac{\varphi^{* *}}{\varphi^{*}}\right)^{1-\sigma}\left(\frac{f_{2}}{f_{1}}-1\right)+1\right]^{\frac{1}{\sigma-\psi}}\left(\frac{a}{1-a}\right)^{\frac{\psi}{\sigma-\psi}} b^{\frac{\psi-1}{\sigma-\psi}} .
$$

This expression implicitly defines the equilibrium value of $\varphi^{* *} / \varphi^{*}>1$. In the framework developed here productivity, $\varphi$, is the heterogeneous firm characteristic and fixed costs, variable costs and the weight of products in demand, $\left\{f_{i}, b_{i}, a\right\}$, are the diverse product attributes that determine the endogenous selection of products by firms. The effect of each of these parameters on product choice is mediated by the elasticity of substitution between products, $\psi$, the elasticity of substitution between varieties of each product, $\sigma$, and the degree of skewness of the Pareto distribution, $\gamma$. Increases in the fixed cost of production for product 2 relative to product $1, f_{2} / f_{1}$; increases in the variable cost of production for product 2 relative to product $1, b$; and increases in the weight of product 1 in consumer utility, $a$, increase $\varphi^{* *} / \varphi^{*}$ and reduce the range of productivities where product 2 is produced.

The point that product choice is shaped by the interaction of heterogeneous firm and product characteristics and results in a non-random distribution of firms across products is clearly very general. In the remainder of this section, we trace the bias in firm and industry productivity measures that inevitably result unless the empirical researcher can observe which products are made by which firms or can combine a structural model of product choice and industry evolution with an observable exogenous variable that determines firm product choice but does not affect firm performance conditional on product choice.

\subsection{Product Choice and Firm Productivity}

Standard superlative productivity indices (Caves et al. 1982a,b) assume constant returns to scale and perfect competition to derive a primal measure of productivity from the relationship between output and factor inputs or a dual measure of productivity from the relationship between prices and factor costs. With a single factor of production, as in the model developed here, the dual productivity index takes the form:

$$
\ln A(\omega)=\ln w-\ln p(\omega)
$$


where $A(\omega)$ denotes total factor productivity (TFP) and $\omega$ indexes firms. Therefore, a lower value of prices relative to factor costs corresponds to a higher value of TFP.

The true relationship between prices, wages and firm productivity in the model is governed by the equilibrium pricing rule in equation (6) so that the superlative index number measure of TFP captures not only true differences in firm productivity $\varphi(\omega)$, but also variation in the variable cost of production parameter $b_{i}$ across products, and the size of the mark-up of price over marginal cost $(\sigma /(\sigma-1))$ :

$$
\ln A(\omega)=\ln \left[\left(\frac{\sigma-1}{\sigma}\right) \frac{\varphi(\omega)}{b_{i}}\right]=\ln \left[\frac{\rho \varphi(\omega)}{b_{i}}\right] .
$$

Proposition 3 Measured productivity differences across firms can be decomposed into a component due to true differences in firm productivity and a component due to variation in production technique across products.

Proof. See Appendix.

Corollary 1 If the high fixed cost product has lower variable costs, non-random selection into products by firms magnifies the measured dispersion of productivity across firms.

Proof. See Appendix.

From equations (27) and (28), the measured relative productivity of two firms making different products will reflect not only the true difference in productivity between the firms, $\varphi^{\prime} / \varphi^{\prime \prime}$, but also the difference in variable costs between the two products, $b \equiv b_{2} / b_{1}$. Since high productivity firms make high fixed cost products, it follows that if high fixed costs are associated with low variable costs, endogenous product choice will magnify the measured dispersion in productivity across firms. Conversely, if high fixed costs are associated with high variable costs, endogenous product choice will compress the measured dispersion in productivity levels across firms.

Therefore, when firms endogenously choose between products with heterogeneous techniques, standard index number measures of TFP will be systematically biased. While we have shown the bias using a dual measure based on prices and factor costs, the same bias will affect the primal measure based on output and factor inputs. 
Though these standard TFP measures are widely used in empirical work, it might be objected that there are a number of more sophisticated measures of TFP that seek to control for a variety of measurement issues. In particular, it is possible to correct for imperfect competition (Hall 1988, Roeger 1995), increasing returns to scale (Klette and Griliches 1995), and the absence of firm-specific price data (Klette and Griliches 1995, Levinsohn and Melitz 2002, De Loecker (2005) and Martin 2005). Furthermore, rather than measuring productivity using index numbers, a related literature obtains TFP measures from production function estimation (Olley and Pakes 1996, Levinsohn and Petrin 2003).

While these techniques control for many sources of measurement error, we now show that they do not eliminate the bias in productivity measures due to endogenous product choice. Measures of imperfect competition control for the size of the markup of price over marginal cost. Since to keep the algebra particularly tractable, we have assumed both products have the same elasticity of demand across varieties, this adjustment would eliminate the term $((\sigma-1) / \sigma)$ from measured TFP in equation (28). However, controlling for the size of the mark-up does not eliminate the bias induced by different products having different production techniques, captured here in the variation in the variable cost of production parameter $b_{i}$. Furthermore, if we enriched the model to allow different products to have different elasticities of demand, mark-ups would need to be measured at the product level whereas, in much empirical work, mark-ups are estimated for the industry as a whole.

Second, controlling for increasing returns to scale will not eliminate the bias in productivity measures. The problem is that the fixed and variable cost parameters which determine observed productivity and the degree of increasing returns to scale vary across products. Any productivity measure that does not control for this variation will be biased. Third, the bias does not arise from price deflators only being available at the industry-level and output being measured using revenue rather than quantity data. The biases we derived above assumed that prices were observed at the firm-level and we will show in the discussion of production function estimation below that primal productivity measures will be systematically biased even if the physical quantity of output is observed at the firm-level.

Fourth, production function estimation will not eliminate the biases in productivity measures derived here, even assuming that one can control for the simultaneity of firm input choice as in the estimation techniques of Olley and Pakes (1996) and Levinsohn and Petrin (2003). The model implies the following relationship between 
physical quantities of output and factor inputs:

$$
\ln q_{i}(\omega)=\ln \varphi(\omega)-\ln b_{i}+\ln \left[l_{i}(\omega)-f_{i}(\omega)\right]
$$

where $i$ indexes products and $\omega$ indexes firms.

The identifying assumption typically made in production function estimation is that production techniques are the same across firms up to a Hicks-neutral productivity shifter. Making this assumption, and imposing common slope coefficients on the factor inputs, the residual from the production function estimation is used as a measure of TFP. In the one-factor model considered here, the regression specification would be:

$$
\ln q(\omega)=\alpha+\beta \ln [l(\omega)-\gamma]+u(\omega)
$$

where the identifying assumption is that $\beta$ and $\gamma$ are the same across firms within industries, and where the residual $u(\omega)$ is the measure of TFP.

This specification uses information on the physical quantity of output and allows for increasing returns to scale. Nonetheless, the estimation will still yield biased measures of firm productivity because it does not control for the fact that firms make different products within the industry and these products vary in terms of their production techniques. The residual $u(\omega)$ will capture true variation in firm productivity $\varphi(\omega)$ as well as variation in fixed and variable cost parameters across products, $b_{i}$ and $f_{i}$.

The fundamental problem afflicting all of the productivity measures considered in this section is that firms make choices about disaggregated products and researchers have typically used information about more aggregate industry activity at the firm. The disaggregate products potentially vary both in production technique and in how they enter demand. To eliminate the bias in dual and primal measures of productivity would require the researcher to have firm-product level information on which products are made by firms, the prices of each product, the price of factors used to produce each product, the quantity of each product and the factor inputs used to produce each product. These conditions will be met in a few industries where highly detailed data are available, but are typically not met in the census and survey data on plants and firms widely used by empirical researchers across fields as diverse as labor economics, development economics, industrial organization and international trade.

In the absence of perfect data with firm-product line information, we consider two examples where firm productivity can still be estimated consistently. If the researcher can sort firms (or plants) into groups that make a single product, it becomes possible 
to measure productivity across firms making the same product. Either superlative index numbers or production function estimation can be employed. Since the product is the same across firms, one has eliminated the bias introduced into productivity measures as a result of endogenous product choice. One would still need to control for the measurement and estimation problems highlighted above: imperfect competition, increasing returns to scale, the absence of firm-specific price data and the availability of revenue rather than quantity data, and the simultaneity of factor input choice.

Alternatively, if the researcher knows which firms (or plants) make which products, consistent estimates of firm productivity may be obtained through production function estimation by allowing the parameters of the production technology to vary across firms making different products. Again one would still need to control for the measurement and estimation issues highlighted above. In particular, the methodologies of Olley and Pakes (1996) and Levinsohn and Petrin (2003) control for the simultaneity of firm input use. The techniques of Levinsohn and Melitz (2002) address the absence of firm-specific price deflators, although the implementation of these techniques would now require product rather than industry-specific price deflators.

These two examples have empirical relevance, since the panel data on U.S. manufacturing in the LRD includes information on which products are produced and the value of shipments by product for individual plants that might be incorporated into production function estimation. ${ }^{12}$

\subsection{Product Choice and Industry Productivity}

Measured industry productivity is the revenue-share weighted average of measured firm productivity. Biases in measured firm productivity therefore lead to biases in measured industry productivity. We illustrate this point using the standard superlative index number measure of productivity introduced in the previous section (equations (27) and (28)). However, as noted above, similar biases affect other measures of productivity where firm product choice cannot be explicitly observed or controlled for within an appropriate structural model. From the expression for equilibrium firm revenue in equation (7), the revenue share of a firm producing product $i$ with measured productivity $A_{i}(\varphi)=\left(\rho / b_{i}\right) \varphi$ is:

$$
s_{i}\left[A_{i}(\varphi)\right] \equiv \frac{r_{i}\left[A_{i}(\varphi)\right]}{R}=\alpha_{i}(\mathcal{P}) A_{i}(\varphi)^{\sigma-1} P_{1}^{\sigma-1}
$$

\footnotetext{
${ }^{12}$ See Bernard et al. (2005) for an empirical analysis of variation in product mix across firms and over time for the U.S. manufacturing sector.
} 
Therefore, measured industry productivity may be expressed as:

$$
\bar{A}=\int_{\varphi^{*}}^{\varphi^{* *}} \frac{s_{1}\left[A_{1}(\varphi)\right] A_{1}(\varphi) g(\varphi) d \varphi}{G\left(\varphi^{* *}\right)-G\left(\varphi^{*}\right)}+\int_{\varphi^{* *}}^{\infty} \frac{s_{2}\left[A_{2}(\varphi)\right] A_{2}(\varphi) g(\varphi) d \varphi}{1-G\left(\varphi^{* *}\right)} .
$$

Proposition 4 Measured industry productivity depends on the weight of products in consumer utility and changes in these weights will result in measured industry productivity growth or decline.

Proof. See Appendix.

The weight of products in consumer utility, $a$, influences measured industry productivity through a number of routes. First, these weights determine the zero profit and product indifference cutoff productivities, $\varphi^{*}$ and $\varphi^{* *}$, and hence the range of productivities where each product is produced. The product with a lower variable cost of production will have a higher measured productivity in equation (27). Therefore, other things equal, the greater the range of productivities over which the lower variable cost product is produced, the higher measured industry productivity. Second, the weight of each product in consumer utility will affect the share of revenue received by a firm making each product. Other things equal, the larger the share of revenue allocated to the product with the lower variable cost of production, the higher measured industry productivity.

Since an increase in the weight of the low variable cost product in consumer utility increases both the range of productivities where the product is produced and the share of revenue received by producers of the product, it follows that a rise in this weight generates measured industry productivity growth. Conversely, a fall in the low variable cost product's weight in consumer utility generates a decline in measured industry productivity. Even though true firm-level productivity remains unchanged, the endogenous re-sorting of firms across products with different production techniques results in changes in measured industry productivity.

Because firms choose products at a more disaggregated level than observed by the empirical researcher and these products differ systematically in terms of their technology, the demand-side becomes important in determining measured industry productivity. Measured industry productivity depends on two sets of supply-side considerations, the true distribution of productivity across firms and the parameters of the production technology of the two products, as well as patterns of consumer demand which influence heterogeneous firms' non-random decision of which products to produce. 


\section{Deregulation and Industry Dynamics}

The response of industries to policy reforms such as deregulation has been a major focus of much recent research. In this section, we use the theoretical model of industry equilibrium to show that endogenous product choice provides an important additional decision margin along which heterogeneous firms adjust to industry deregulation, alongside firm entry and exit and changes in the composition of output across firms of different productivities within existing product markets. We show how the endogenous sorting of firms across products may result in either measured productivity growth or decline at the firm and industry level. We illustrate these responses in the simplest possible setting by assuming a Pareto productivity distribution so that relative prices and the relative value of the productivity cutoffs are determined according to equations (25) and (26).

Proposition 5 A reduction in entry barriers, $f_{e}$, leads to:

(a) A rise in the zero profit productivity cutoff, $\varphi^{*}$, and a rise in the product indifference productivity cutoff, $\varphi^{* *}$

(b) A rise in true average industry productivity due to exit by low productivity firms

(c) Changes in measured firm productivity at surviving firms that switch products

(d) Changes in measured industry productivity due to exit by low productivity firms and switches in products at surviving firms

Proof. See Appendix.

We begin by tracing the comparative statics for the endogenous variables of the model and for true industry productivity, before examining the implications for measured firm and industry productivity. As summarized in Table 3 and proved in the Appendix, a reduction in barriers to entry (a reduction in the sunk entry cost $f_{e}$ ) increases both productivity cutoff levels, thus raising true average productivity in each product market and for the industry as a whole. The ratio of the productivity cutoffs, the relative price of the products, the mass of firms producing each product, and average profitability are unchanged. The expected value of entry falls and welfare unambiguously rises.

Intuition for these results can be obtained by considering the impact of the reduction in barriers to entry at the initial steady-state equilibrium. As the sunk entry cost falls below the expected value of entry, a larger mass of firms, $M_{e}$, will enter the industry. For given values of $\varphi^{*}$ and $\varphi^{* *}$, a larger mass of entrants implies a larger 
mass of firms with productivity realizations high enough to produce in each market. This rise in the mass of firms producing in each market reduces ex post profitability.

The reduction in ex post profitability means that some low productivity firms are now no longer able to cover the fixed costs of producing product 1 . Hence, in equilibrium the zero-profit productivity cutoff $\varphi^{*}$ rises. As $\varphi^{*}$ rises for a given value of $\varphi^{* *}$, this reduces the mass of firms in product 1 relative to the mass of firms in product 2 , thereby increasing product 1's relative profitability. Hence, some higher productivity firms that previously made product 2 now find it more profitable to produce the low fixed cost product 1 and $\varphi^{* *}$ also rises.

The equilibrium ratio of the two productivity cutoffs, $\varphi^{* *} / \varphi^{*}$, is independent of the sunk costs of entry, and hence $\varphi^{* *}$ rises by the same proportion as $\varphi^{*}$. With a Pareto productivity distribution, this leaves the relative price of the two products, $\mathcal{P}$, unchanged.

The implications of the change in barriers to entry for the two productivity cutoffs are summarized graphically in Figure 3. The rise in both $\varphi^{*}$ and $\varphi^{* *}$ means that some low productivity firms that previously made product 1 exit, while some higher productivity firms that previously made product 2 switch to product 1 . For both these reasons, weighted average productivity in product $1, \widetilde{\varphi}_{1}$, will rise. Since the firms that switch from product 2 to product 1 are of lower productivity than those who continue to make product 2 , weighted average productivity in product $2, \widetilde{\varphi}_{2}$, will also rise.

The rise in $\varphi^{*}$ and $\varphi^{* *}$ reduces the mass of firms with productivity realizations high enough to produce in each market for a given mass of firms, $M_{e}$, that enter. With a Pareto distribution, this effect exactly offsets the larger mass of firms entering the industry, so that the mass of firms producing in each product market $\left(M_{1}, M_{2}\right)$, average firm revenue $\left(\bar{r}_{1}, \bar{r}_{2}\right)$, and average ex post profitability $\left(\bar{\pi}_{1}, \bar{\pi}_{2}\right)$ are unchanged at the new steady-state equilibrium.

The expected value of entry, $v_{e}$, falls to equal the new lower sunk costs of entry, $f_{e}$, because the rise in $\varphi^{*}$ and $\varphi^{* *}$ reduces the probability of a firm having a productivity realization high enough to be able to profitably manufacture either product 1 or product 2. Welfare per worker, $W$, rises because, although the mass of firms and hence product varieties is unchanged, the rise in average productivity within each product market reduces average variety prices and hence consumer price indices.

The implications of the fall in entry barriers for true productivity can be summarized as follows. True productivity at the firm-level remains unchanged because it is drawn from a distribution at the point of entry. True average industry pro- 
ductivity rises due to exit by low productivity firms. Besides these implications for true productivity, endogenous changes in product by surviving firms have additional consequences for measured productivity at both the firm and industry level.

Consider the standard superlative index number measures of productivity introduced in equation (28) for the firm and equation (32) for the industry. Higher productivity surviving firms that switch from product 2 to product 1 may experience either measured productivity growth or decline depending on whether the variable cost of production for product 1 is lower or higher than the variable cost of production for product 2 respectively. For all other surviving firms, measured firm productivity will remain unchanged.

Measured industry productivity will be influenced both by exit by low productivity firms and by endogenous changes in product at surviving firms. With an unchanged relative price for the two products, $\mathcal{P}$, the share of revenue received by a firm making a given product in equation (32) will remain unchanged. If product 1 has a lower variable cost of production than product 2 , switches in products will reinforce the increase in measured average industry productivity due to exit by low productivity firms. If product 1 has a higher variable cost of production than product 2 , the endogenous changes in products will reduce measured average industry productivity, and if this reduction is large enough to offset the effect of exit by low productivity firms, measured industry productivity may decline.

We have illustrated the point that endogenous choice between heterogeneous products provides a new margin of adjustment to deregulation that influences measured firm and industry productivity using standard superlative index number measures of productivity assuming perfect competition and constant returns to scale. However, as we showed above, similar biases will affect any other productivity measure where information on price, cost, output and input is not available at the firm-product level or where endogenous product choice cannot be modelled using a structural model of industry equilibrium.

These points are not specific to the particular theoretical framework considered here. Similar measurement problems will be present whenever firm product choice is made at a more finely detailed level than observed by empirical researchers and where products differ in terms of production technique or the way in which they enter demand. Explicitly modelling the endogenous sorting of firms across products within industries will help to deepen our understanding of how industries respond to deregulation and the heterogeneous responses of measured productivity across firms and industries to exogenous policy reform. 


\section{Conclusions}

Firms' decisions about what products to produce are often made at a more disaggregate level than observed by empirical researchers. When products differ in production techniques or the way in which they enter demand, this aggregation problem introduces a bias into standard productivity measures. In general, when products vary in production technique, the standard identifying assumption that technologies are the same across firms within industries up to a Hicks-neutral or factor augmenting productivity shifter will be violated. As a result, productivity measures will be biased even if firm-specific data is available on prices and costs and on the physical quantity of output rather than revenue.

The paper develops a theoretical model of industry equilibrium where endogenous self-selection into products may magnify measured productivity dispersion across firms within industries, and where changes in the relative demand for products may generate measured industry productivity growth. Measured productivity reflects not only the true underlying characteristics of firms but also their non-random decision of what product to produce. The endogenous sorting of firms across products influences the response of industries to exogenous policy reforms such as industry deregulation. Reductions in barriers to entry raise true industry productivity due to increased exit by low productivity firms, but measured firm and industry productivity may either rise or decline due to endogenous switches by surviving firms between products with heterogeneous characteristics.

Our analysis suggests a number of areas for further empirical inquiry. Researchers should make use of existing data on the evolving product mix of firms. In some instances these data may only be available for particular markets and industries, but even comprehensive data sources such as the U.S. Census Bureau's Longitudinal Research Database contain much information on firms' product-level production. Bernard et al. (2005), for example, find that U.S. firms within industries vary substantially in terms of their product mix.

Further theoretical research is also warranted, particularly in developing richer models of industry dynamics that allow firms to choose the number and type of goods they produce. While product choice introduces an additional dimension of firm heterogeneity to track over time, it promises to yield new insights into how firms, industries and economies respond to exogenous changes in the economic environment and policy regime. 


\section{References}

Baily, N., Hulten, C. and Campbell, D. (1992) "Productivity Dynamics in Manufacturing Plants", Brookings Papers on Economic Activity, Microeconomics, 187-267.

Bernard, Andrew B., Stephen Redding, and Peter K. Schott, (2005) "Multi-Product Firms, Industry Mix, and Product Switching", Tuck School of Business at Dartmouth, mimeo.

Berry, S., Levinsohn, J. and Pakes, A. (1995) "Automobile Prices in Market Equilibrium", Econometrica, 63, 841-890.

Caves, D., Christensen, L. and Diewert, E. ( 1982a) "The Economic Theory of Index Numbers and the Measurement of Input, Output and Productivity", Econometrica, 50(6): 1393-1414.

Caves, D., Christensen, L., and Diewer,t E. ( 1982b) "Multilateral Comparisons of Output, Input and Productivity Using Superlative Index Numbers", Economic Journal, 92, 73-86.

Davis, S. J . and Haltiwanger, J . (1991) "Wage Dispersion between and within U.S. Manufacturing Plants, 1963-86", Brookings Papers on Economic Activity, Microeconomics, 115-180.

De Loecker, J. (2005) "Product Differentiation, Multi-Product Firms and Structural Estimation of Productivity", K.U. Leuven, mimeograph.

Disney, R, Haskel, J and Heden, Y (2003) "Restructuring and Productivity Growth in UK Manufacturing", Economic Journal, 113, 666694 .

Dunne, T., Roberts M. J., and Samuelson L. (1989) "The Growth and Failure of U.S. Manufacturing Plants", Quarterly Journal of Economics, 104(4): 671-98.

Ericsson, R. and Pakes, A. (1995) "Markov-Perfect Industry Dynamics: A Framework for Empirical Work", Review of Economic Studies, 62(1), 53-82.

Foster, L., Haltiwanger, J. and Krizan, C. (2002) "The Link Between Aggregate and Micro Productivity Growth: Evidence from Retail Trade", NBER Working Paper, \#9120. 
Foster, L., Haltiwanger, J. and Krizan, C. (2001) "Aggregate Productivity Growth: Lessons from Microeconomic Evidence" in New Developments in Productivity Analysis, Hulten, Charles R., Dean, Edwin R., Harper, Michael J. (eds), NBER Studies in Income and Wealth, vol. 63. Chicago and London: University of Chicago Press.

Goldberg, P. K. (1995) "Product Differentiation and Oligopoly in International Markets: The Case of the U.S. Automobile Industry", Econometrica 891-951.

Hall, R. (1988) "The Relationship Between Price and Marginal Cost in US Industry", Journal of Political Economy, 96(5): 921-947.

Hausman, J. (1997) "Valuation of New Goods under Perfect and Imperfect Competition" i n Bresnahan, T. and Gordon, R. (eds), The Econ omics of N ew Goods, Chicago University Press and NBER.

Hopenhayn, H. (1992) "Entry, Exit, and Firm Dynamics in Long Run Equilibrium", Econometrica, 60(5): 1127-1150.

Hotelling, H. (1929) "Stability in Competition", Economic Journal, 39: 41-57.

Jovanovic, B. (1982) "Selection and the Evolution of Industry", Econometr ica, vol. 50(3): 649-670.

Katayama, H., Lu, S. and Tybout, J . (2003) "Why Plant-Level Productivity Studies are Often Misleading, and an Alternative Approach to Interference", NBER Working Paper, 9617.

Klette, T. and Griliches, Z. (1996) "The Inconsistency of Common Scale Estimators when Output Prices are Unobserved and Endogenous", Journal of Applied Econometrics, 11: 343-361.

Lancaster, K. (1966) "A New A pproach to Consumer Theory", J ournal of P olitical Economy, 74: 132-157.

Levinsohn, J. and Melitz, M. (2002) "Productivity in a Differentiated Products Market Equilibrium", Harvard University, mimeograph.

Levinsohn, J. and Petrin, A. (2003) "Estimating Production Functions Using Inputs to Control for Unobservables", Review of Economic Studies, 70: 317-341. 
Martin, R. (2005) "Computing the True Spread", Centre for Economic Performance Discussion Paper, 0692.

Melitz, M. J. (2003) "The Impact of Trade on Intra-Industry Reallocations and Aggregate Industry Productivity", Econometrica 71: 1695-1725.

Olley, S. G. and Pakes, A. (1996) "The Dynamics of Productivity in the Telecommunications Equipment Industry", Econometrica, 64(6): 1263-1297.

Pavcnik, N. (2002) "Trade Liberalization, Exit, and Productivity Improvement: Evidence from Chilean Plants", Review of Economic Studies, 69(1): 245-276.

Petrin, A. (2002) "Quantifying the Benefits of New Products: The Case of the Minivan", Journal of Political Economy, 110(4): 705-729.

Roeger, W. (1995) "Can Imperfect Competition Explain the Difference Between Primal and Dual Productivity Measures? Estimates for US Manufacturing", Journal of Political Economy, 103(2): 316-330.

Shaked, A. and Sutton, J . (1982) "Imperfect Information, Perceived Quality and the Formation of Professional Groups", Journal of Economic Theory 27(1): $170-181$.

Spence, A. M. (1976) "Product Differentiation and Welfare", A meri can Economic Review, 66(2): 407-414.

Sutton, J. (1998) Technology and $\mathrm{M}$ arket Structure: Theory and $\mathrm{H}$ istory, MIT Press, Cambridge, Massachusetts.

Syverson, C. (2004) "Market Structure and Productivity: A Concrete Example", Journal of Political Economy, 112(6): 1181-222.

Trajtenberg, M. (1989) "The Welfare Analysis of Product Innovations, with an Application to Computed Tomography Scanners", Journal of Political Economy, 97: 444-479.

Tybout, J., de Melo, J. and Corbo, V. (1991) "The Effects of Trade Reforms on Scale and Technical Efficiency: New Evidence from Chile", Journal of International Economics, 31(3-4): 231-250. 
U.S. Census Bureau ( 1996) "1992 Census of Manufactures: Numerical List of Manufactured and Mineral Products." U.S. Government Printing Office, Washington DC. http://www.census.gov/prod/2/manmin/mc92-r-1.pdf 


\section{A Appendix: Theoretical Derivations}

\section{A1. Weighted Average Productivity and Average Profitability}

$$
\begin{aligned}
\widetilde{\varphi}_{1}\left(\varphi^{*}, \varphi^{* *}\right) & =\left[\frac{1}{G\left(\varphi^{* *}\right)-G\left(\varphi^{*}\right)} \int_{\varphi^{*}}^{\varphi^{* *}} \varphi^{\sigma-1} g(\varphi) d \varphi\right]^{1 /(\sigma-1)} \\
\widetilde{\varphi}_{2}\left(\varphi^{* *}\right) & =\left[\frac{1}{1-G\left(\varphi^{* *}\right)} \int_{\varphi^{* *}}^{\infty} \varphi^{\sigma-1} g(\varphi) d \varphi\right]^{1 /(\sigma-1)}
\end{aligned}
$$

Using the relationship between the revenues of firms producing varieties in the same and in different markets, as well as the expression for the zero-profit productivity cutoff and the CES expenditure share, average profit in the two product markets, $\bar{\pi}_{i}=\pi_{i}\left(\tilde{\varphi}_{i}\right)$ may be written as follows:

$$
\begin{aligned}
\bar{\pi}_{1}\left(\varphi^{*}, \varphi^{* *}\right) & =\left[\left(\frac{\widetilde{\varphi}_{1}(\cdot)}{\varphi^{*}}\right)^{\sigma-1}-1\right] f_{1} \\
\bar{\pi}_{2}\left(\varphi^{*}, \varphi^{* *}, \mathcal{P}\right) & =\left[\left(\frac{1-a}{a}\right)^{\psi}\left(\frac{1}{b} \frac{\widetilde{\varphi}_{2}(\cdot)}{\varphi^{*}}\right)^{\sigma-1} \mathcal{P}^{\sigma-\psi}-\frac{f_{2}}{f_{1}}\right] f_{1}
\end{aligned}
$$

\section{A2. Proof of Proposition 1}

Proof. We begin by determining the equilibrium sextuple: $\left\{\varphi^{*}, \varphi^{* *}, P_{1}, P_{2}, R_{1}, R_{2}\right\}$. First, we use the relative supply and relative demand relationships in equations (21) and (22) to establish that there exist unique equilibrium values of $\varphi^{* *} / \varphi^{*}$ and $\mathcal{P}$. Rearranging the product supply relationship, we obtain:

$$
\mathcal{P}=b^{\frac{\sigma-1}{\sigma-\psi}}\left(\frac{a}{1-a}\right)^{\frac{\psi}{\sigma-\psi}}\left[\left(\frac{\varphi^{* *}}{\varphi^{*}}\right)^{1-\sigma}\left(\frac{f_{2}}{f_{1}}-1\right)+1\right]^{\frac{1}{\sigma-\psi}} .
$$

Since $\sigma>1$, the right-hand side is monotonically decreasing in $\varphi^{* *} / \varphi^{*}$ and is graphed in $\left(\mathcal{P}, \varphi^{* *} / \varphi^{*}\right)$ space in Figure 2. $\mathcal{P}$ takes the value $\left(f_{2} / f_{1}\right)^{1 /(\sigma-\psi)}(a /(1-a))^{\psi /(\sigma-\psi)} b^{(\sigma-1) /(\sigma-\psi)}>$ 0 at $\varphi^{* *} / \varphi^{*}=1$ and converges to a lower value of $(a /(1-a))^{\psi /(\sigma-\psi)} b^{(\sigma-1) /(\sigma-\psi)}>0$ as $\varphi^{* *} / \varphi^{*}$ tends to infinity.

Turning now to the product demand relationship (equation (22)), the left-hand side is monotonically increasing in $\varphi^{* *} / \varphi^{*}$ and is also graphed in $\left(\mathcal{P}, \varphi^{* *} / \varphi^{*}\right)$ space below. As $\varphi^{* *} / \varphi^{*}$ approaches $1, \mathcal{P}$ converges to 0 . As $\varphi^{* *} / \varphi^{*}$ tends to infinity, $\mathcal{P}$ converges to $\infty$. 
Therefore, as shown in 2, there exists a unique equilibrium value of $\left(\mathcal{P}, \varphi^{* *} / \varphi^{*}\right)$ where both the relative supply and relative demand relationships are satisfied and where $\varphi^{* *} / \varphi^{*}>1$.

Given values of $\Lambda \equiv \varphi^{* *} / \varphi^{*}$ and $\mathcal{P}$, equation (23) is monotonically decreasing in $\varphi^{*}$ :

$$
\begin{aligned}
& \frac{d v_{e}}{d \varphi^{*}}<0 \\
& \Leftrightarrow \underbrace{\frac{f_{1}}{\delta} \int_{\varphi^{*}}^{\Lambda \varphi^{*}} \varphi^{\sigma-1}(1-\sigma)\left(\varphi^{*}\right)^{-\sigma} g(\varphi) d \varphi}_{\text {Term A }}+\underbrace{\frac{f_{1}}{\delta} \Lambda\left[\Lambda^{\sigma-1}-1\right] g\left(\Lambda \varphi^{*}\right)}_{\text {Term B }} \\
& +\underbrace{\frac{f_{1}}{\delta} \int_{\Lambda \varphi^{*}}^{\infty}\left(\frac{1-a}{a}\right)^{\psi}\left(\frac{1}{b}\right)^{\sigma-1} \mathcal{P}^{\sigma-\psi} \varphi^{\sigma-1}(1-\sigma)\left(\varphi^{*}\right)^{-\sigma} g(\varphi) d \varphi}_{\text {Term C }} \\
& \underbrace{\frac{f_{1}}{\delta} \Lambda\left[\left(\frac{1-a}{a}\right)^{\psi}\left(\frac{1}{b}\right)^{\sigma-1} \mathcal{P}^{\sigma-\psi} \Lambda^{\sigma-1}-\frac{f_{2}}{f_{1}}\right] g\left(\Lambda \varphi^{*}\right)}_{\text {Term D }}<0
\end{aligned}
$$

The sum of Terms B and D may be written as,

$$
\frac{f_{1}}{\delta} \Lambda g\left(\Lambda \varphi^{*}\right)\left[\left(\frac{f_{2}}{f_{1}}-1\right)-\Lambda^{\sigma-1}\left(\left(\frac{1-a}{a}\right)^{\psi}\left(\frac{1}{b}\right)^{\sigma-1} \mathcal{P}^{\sigma-\psi}-1\right)\right] .
$$

where, from the definition of $\Lambda$ in equation (21), the term in square parentheses is exactly equal to zero. Since $\sigma>1$, Terms A and C in equation (37) are negative. Hence, $\frac{d v_{e}}{d \varphi^{*}}<0$ for all $\varphi^{*}$. Furthermore, as $\varphi^{*} \rightarrow 0$ in equation (23), $v_{e} \rightarrow \infty$. As $\varphi^{*} \rightarrow \infty, v_{e} \rightarrow 0$. Together, equations (21), (22) and (23) determine unique equilibrium values of the three unknowns $\left(\varphi^{*}, \varphi^{* *}, \mathcal{P}\right)$. Since $\varphi^{*}>0$ and $\varphi^{* *}>\varphi^{*}$ both products are indeed produced in equilibrium.

These three elements of the equilibrium vector are sufficient to determine weighted average productivity, $\widetilde{\varphi}_{1}$ and $\widetilde{\varphi}_{2}$, in equation (33), as well as average revenue and hence average profitability, $\bar{\pi}_{1}$ and $\bar{\pi}_{2}$, in equations (34) and (35).

As shown in the main text, the steady-state stability and free entry conditions (equations (17), (18) and (16)) imply that total revenue, $R$, is equal to total payments to labor used in both entry and production, $L$.

Revenue in each product market may be determined from the CES expenditure share (equation (4)) at the equilibrium value of relative prices, $\mathcal{P}$, for which we solved above: $R_{1}=\alpha_{1}(\mathcal{P}) L$ and $R_{2}=(1-\alpha(\mathcal{P})) L$. 
From consumer and producer optimization, the price indices, $P_{1}$ and $P_{2}$, may be written as functions of the mass of firms, $M_{1}$ and $M_{2}$, and the price charged by a firm with weighted average productivity, $p_{1}\left(\widetilde{\varphi}_{1}\right)$ and $p_{2}\left(\widetilde{\varphi}_{2}\right)$ :

$$
\begin{aligned}
& P_{1}=\left(M_{1}\right)^{\frac{1}{1-\sigma}} p_{1}\left(\widetilde{\varphi}_{1}\right)=\left(\frac{\alpha_{1}(\mathcal{P}) L}{\sigma\left(\bar{\pi}_{1}+f_{1}\right)}\right)^{\frac{1}{1-\sigma}} \frac{1}{\rho \widetilde{\varphi}_{1}} \\
& P_{2}=\left(M_{2}\right)^{\frac{1}{1-\sigma}} p_{2}\left(\widetilde{\varphi}_{2}\right)=\left(\frac{\left(1-\alpha_{1}(\mathcal{P})\right) L}{\sigma\left(\bar{\pi}_{2}+f_{2}\right)}\right)^{\frac{1}{1-\sigma}} \frac{1}{\rho \widetilde{\varphi}_{2}}
\end{aligned}
$$

where we have used $M_{i}=R_{i} / \bar{r}_{i}$ and $\left(\bar{\pi}_{1}, \bar{\pi}_{2}, \widetilde{\varphi}_{1}, \widetilde{\varphi}_{2}\right)$ were determined above. We have thus characterized the equilibrium sextuple $\left\{\varphi^{*}, \varphi^{* *}, P_{1}, P_{2}, R_{1}, R_{2}\right\}$.

We now show that all other endogenous variables of the model may be derived from the equilibrium sextuple $\left\{\varphi^{*}, \varphi^{* *}, P_{1}, P_{2}, R_{1}, R_{2}\right\}$.

From equation (19), $\left(M_{1}, M_{2}\right)$ can be expressed as functions of the price indices $\left(P_{1}, P_{2}\right)$ and weighted average productivity $\left(\widetilde{\varphi}_{1}, \widetilde{\varphi}_{2}\right)$ which is determined by $\left(\varphi^{*}, \varphi^{* *}\right)$ alone. From the analysis in the main text, $M_{e}=\Pi / f_{e}=\left[M_{1} \bar{\pi}_{1}+M_{2} \bar{\pi}_{2}\right] / f_{e}$, where $\left(M_{1}, M_{2}\right)$ have just been determined and $\left(\bar{\pi}_{1}, \bar{\pi}_{2}\right)$ can be derived from $\left(\varphi^{*}, \varphi^{* *}, \mathcal{P}\right)$.

Total payments to labor used in production in product market $i$ equal the difference between revenue, $R_{i}$, and total firm profits, $\Pi_{i}$, in that market. Therefore:

$$
\begin{aligned}
& L_{p 1}=R_{1}-\Pi_{1}=R_{1}-\left(M_{1} \bar{\pi}_{1}\right) \\
& L_{p 2}=R_{2}-\Pi_{2}=R_{2}-\left(M_{2} \bar{\pi}_{2}\right)
\end{aligned}
$$

where we have used the choice of labor as numeraire, $\left(R_{1}, R_{2}\right)$ are part of the equilibrium sextuple, $\left(M_{1}, M_{2}\right)$ were determined above, and $\bar{\pi}_{1}$ and $\bar{\pi}_{2}$ are functions of $\left(\varphi^{*}, \varphi^{* *}, \mathcal{P}\right)$ alone. Payments to labor used in entry are:

$$
L_{e}=M_{e} f_{e}
$$

where $M_{e}$ was determined above.

The first-order conditions for consumer optimization imply:

$$
C_{1}=R \frac{a^{\psi} P_{1}^{-\psi}}{\left[a^{\psi} P_{1}^{1-\psi}+(1-a)^{\psi} P_{2}^{1-\psi}\right]}, \quad C_{2}=R \frac{(1-a)^{\psi} P_{2}^{-\psi}}{\left[a^{\psi} P_{1}^{1-\psi}+(1-a)^{\psi} P_{2}^{1-\psi}\right]}
$$

where $R=L$ and $\left(P_{1}, P_{2}\right)$ are part of the equilibrium sextuple. 


\section{B Proof of Proposition 2}

Proof. This Proposition follows immediately from the Proof of Proposition 1 where we have established that $\varphi^{*}>0$ and $\varphi^{* *}>\varphi^{*}$.

\section{Proof of Proposition 3}

Proof. The Proposition follows immediately from equation (28). Compare a firm with productivity $\varphi^{\prime}>\varphi^{\prime \prime}$ making product 2 to a firm with productivity $\varphi^{\prime \prime}$ making product 1. Relative measured productivity of the two firms is equal to:

$$
\frac{A\left(\varphi^{\prime}\right)}{A\left(\varphi^{\prime \prime}\right)}=\frac{\varphi^{\prime}}{\varphi^{\prime \prime}} \frac{1}{b}
$$

\section{Proof of Corollary 1}

Proof. The Proposition follows immediately from Propositions 2 and 3 . Since $f_{2}>f_{1}$, product 2 is produced by higher productivity firms. Compare a firm with productivity $\varphi^{\prime}>\varphi^{\prime \prime}$ making product 2 to a firm with productivity $\varphi^{\prime \prime}$ making product 1. If $b_{2}<b_{1}$, then $0<b<1$, and from equation (38):

$$
\frac{A\left(\varphi^{\prime}\right)}{A\left(\varphi^{\prime \prime}\right)}>\frac{\varphi^{\prime}}{\varphi^{\prime \prime}}
$$

\section{E Proof of Proposition 4}

Proof. From equation (31) and (4), an increase in the weight of a product in consumer utility $\{a,(1-a)\}$ raises the share of revenue allocated to a producer of that product and reduces the share of revenue allocated to a producer of the other product. If products differ in terms of their variable cost of production, $A_{2}(\varphi) \neq A_{1}(\varphi)$, an increase in the weight of a product in consumer utility will influence measured industry productivity through the numerators in equation (32).

From equations (21), (22) and (23), an increase in the weight of a product in consumer utility $\{a,(1-a)\}$ will also affect the zero profit and product indifference productivity cutoffs $\left\{\varphi^{*}, \varphi^{* *}\right\}$ and hence the range of productivities over which the two products are produced. The share of revenue received, $s_{i}\left[A_{i}(\varphi)\right]$, and measured productivity, 
$A_{i}(\varphi)$, for a producer of true productivity $\varphi$ vary according to which product $i$ she produces. Therefore, an increase in the weight of the product in consumer utility will also influence measured industry productivity through the productivity ranges over which the integrals in equation (32) are evaluated.

\section{F Proof of Proposition 5}

Proof. (a) The expected value of entry in (23) is monotonically decreasing in the zero-profit productivity cutoff $\varphi^{*}$. Therefore, as barriers to entry are reduced (a reduction in the sunk costs of entry $f_{e}$ ), the zero-profit productivity cutoff $\varphi^{*}$ must rise so as to reduce the expected value of entry equal to the new lower sunk cost. Since $\varphi^{* *}=\Lambda \varphi^{*}$ and $\Lambda$ is unchanged following the fall in the sunk cost of entry, $\varphi^{* *}$ will rise by the same proportion as $\varphi^{*}: d \varphi^{*}>0, d \varphi^{* *}>0$ and $d\left(\varphi^{* *} / \varphi^{*}\right)=0$.

(b) True weighted average productivity in each product market, $\widetilde{\varphi}_{1}$ and $\widetilde{\varphi}_{2}$, is defined in equations (33). If productivity is Pareto distributed, $g(\varphi)=z k^{z} \varphi^{-(z+1)}$ where $k>0$ and $z>0$, it follows that $\varphi^{\sigma-1} g(\varphi)=\xi h(\varphi)$ where $h(\varphi)=\gamma k^{\gamma} \varphi^{-(\gamma+1)}$, $\xi \equiv z k^{z-\gamma} / \gamma$ and $\gamma \equiv z-\sigma+1$. That is, $h(\varphi)$ is a Pareto distribution with minimum productivity $k$ and skewness parameter $\gamma \equiv z-\sigma+1$, where we assume $z>\sigma-1$ which corresponds to an assumption that the variance of firm sales in the model is finite. Combining these results, it follows that weighted average productivity in the two product markets may be expressed as:

$$
\begin{aligned}
& \widetilde{\varphi}_{1}\left(\varphi^{*}, \varphi^{* *}\right)^{\sigma-1}=\frac{H\left(\varphi^{* *}\right)-H\left(\varphi^{*}\right)}{G\left(\varphi^{* *}\right)-G\left(\varphi^{*}\right)}=\frac{z\left(\varphi^{*}\right)^{\sigma-1}}{\gamma}\left[\frac{1-\Lambda^{-\gamma}}{1-\Lambda^{-z}}\right] . \\
& \widetilde{\varphi}_{2}\left(\varphi^{* *}\right)^{\sigma-1}=\frac{1-H\left(\varphi^{* *}\right)}{1-G\left(\varphi^{* *}\right)}=\frac{z\left(\varphi^{* *}\right)^{\sigma-1}}{\gamma} .
\end{aligned}
$$

where $H(\varphi)$ is the cumulative distribution function corresponding to $h(\varphi)$.

Since $\sigma>1$, and using the results for the change in the productivity cutoffs above, $d \widetilde{\varphi}_{1}=\left(d \widetilde{\varphi}_{1} / d \varphi^{*}\right) d \varphi^{*}>0$ and $d \widetilde{\varphi}_{2}=\left(d \widetilde{\varphi}_{2} / d \varphi^{* *}\right) d \varphi^{* *}>0$. Since true weighted average productivity rises in each product market individually, true weighted average productivity in the industry as a whole also rises.

(c) The rise in the product indifference productivity cutoff, implies that some higher productivity surviving firms switch from product 2 to product 1 . From equation (28), the proportional change in measured productivity for a firm of true productivity $\varphi^{\prime}$ that switches from product 2 to product 1 is:

$$
\ln \left(\frac{A_{1}\left(\varphi^{\prime}\right)}{A_{2}\left(\varphi^{\prime}\right)}\right)=\ln \left(\frac{b_{2}}{b_{1}}\right)
$$


which implies measured productivity growth if $b_{1}<b_{2}$ or a measured productivity decline if $b_{2}<b_{1}$.

(d) With a Pareto productivity distribution, the relative price, $\mathcal{P}$, in equation (25) depends solely on $\varphi^{* *} / \varphi^{*}$. We established above that $d\left(\varphi^{* *} / \varphi^{*}\right)=0$ and so $d \mathcal{P}=$ 0 . With an unchanged value of $\mathcal{P}$, the share of revenue received by a firm of a given productivity in a given product market in equation $(31), s_{i}\left[A_{i}(\varphi)\right]$, will remain unchanged. Following the decline in the sunk costs of entry, measured average industry productivity in equation (32) will change due to exit by low productivity firms and due to surviving firms switching from product 2 to product 1 . Exit by low productivity firms will unambiguously raise average industry productivity. Switching products will change a firm's measured productivity, as established in (c), and its share of revenue from producing in another product market, $s_{1}\left[A\left(\varphi^{\prime}\right)\right] \neq s_{2}\left[A\left(\varphi^{\prime}\right)\right]$. Depending on the relative value of $s_{1}\left[A\left(\varphi^{\prime}\right)\right] A\left(\varphi^{\prime}\right)$ and $s_{2}\left[A\left(\varphi^{\prime}\right)\right] A\left(\varphi^{\prime}\right)$, product switching by surviving firms may either raise or reduce measured average industry productivity. The net effect on measured average industry productivity as a result of exit by low productivity firms and changes in products at surviving firms is therefore ambiguous.

\section{G Deregulation Comparative Statics}

Consider the impact of a reduction in barriers to entry (a reduction in the sunk costs of entry $f_{e}$ ) assuming a Pareto productivity distribution: $g(\varphi)=z k^{z} \varphi^{-(z+1)}$, where $k>0$ and $z>0$.

The proof of Proposition 5 established a proportional rise in both productivity cutoffs: $d \varphi^{*}>0, d \varphi^{* *}>0$ and $d\left(\varphi^{* *} / \varphi^{*}\right)=0$. With a Pareto productivity distribution, the relative price, $\mathcal{P}$, in equation (25) depends solely on $\varphi^{* *} / \varphi^{*}$ and so $d \mathcal{P}=0$.

The proof of Proposition 5 established a rise in weighted average productivity in each product market individually, $d \widetilde{\varphi}_{1}=\left(d \widetilde{\varphi}_{1} / d \varphi^{*}\right) d \varphi^{*}>0$ and $d \widetilde{\varphi}_{2}=$ $\left(d \widetilde{\varphi}_{2} / d \varphi^{* *}\right) d \varphi^{* *}>0$, which implies a rise in weighted average productivity in the industry as a whole.

The change in average revenue, $\bar{r}_{i}$, and average profitability, $\bar{\pi}_{i}$, in equations $(34)$ and (35) depends upon the change in the ratios of weighted average productivity, $\widetilde{\varphi}_{1}$ and $\widetilde{\varphi}_{2}$, to the zero-profit productivity cutoff, $\varphi^{*}$ :

$$
\left(\frac{\widetilde{\varphi}_{1}\left(\varphi^{*}, \varphi^{* *}\right)}{\varphi^{*}}\right)^{\sigma-1}=\frac{H\left(\varphi^{* *}\right)-H\left(\varphi^{*}\right)}{\left(\varphi^{*}\right)^{\sigma-1}\left[G\left(\varphi^{* *}\right)-G\left(\varphi^{*}\right)\right]}=\frac{z\left[1-\Lambda^{-\gamma}\right]}{\gamma\left[1-\Lambda^{-z}\right]} .
$$




$$
\left(\frac{\widetilde{\varphi}_{2}\left(\varphi^{*}, \varphi^{* *}\right)}{\varphi^{*}}\right)^{\sigma-1}=\frac{1-H\left(\varphi^{* *}\right)}{\left(\varphi^{*}\right)^{\sigma-1}\left[1-G\left(\varphi^{* *}\right)\right]}=\frac{z \Lambda^{\sigma-1}}{\gamma} .
$$

With $\Lambda$ unchanged, $d \bar{\pi}_{1}=0$ and $d \bar{\pi}_{2}=0$.

The mass of firms producing each product is:

$$
\begin{aligned}
& M_{1}=\frac{R_{1}}{\bar{r}_{1}}=\frac{\alpha_{1}(\mathcal{P}) L}{\sigma\left(\bar{\pi}_{1}+f_{1}\right)} \\
& M_{2}=\frac{R_{2}}{\bar{r}_{2}}=\frac{\left(1-\alpha_{1}(\mathcal{P})\right) L}{\sigma\left(\bar{\pi}_{2}+f_{2}\right)} .
\end{aligned}
$$

Since both relative prices, $\mathcal{P}$, and profitability, $\bar{\pi}_{1}$ and $\bar{\pi}_{2}$, are unchanged: $d M_{1}=0$ and $d M_{2}=0$. Welfare per worker is:

$$
\begin{aligned}
& W=\left[a^{\psi} P_{1}^{1-\psi}+(1-a)^{\psi} P_{2}^{1-\psi}\right]^{\frac{1}{\psi-1}} \\
& P_{1}=\left(\frac{R_{1}}{\bar{r}_{1}}\right)^{\frac{1}{1-\sigma}} p_{1}\left(\widetilde{\varphi}_{1}\right)=\frac{\alpha_{1}(\mathcal{P}) L}{\sigma\left(\bar{\pi}_{1}+f_{1}\right)} \frac{1}{\rho \widetilde{\varphi}} \\
& P_{2}=\left(\frac{R_{2}}{\bar{r}_{2}}\right)^{\frac{1}{1-\sigma}} p_{2}\left(\widetilde{\varphi}_{2}\right)=\frac{\left(1-\alpha_{1}(\mathcal{P})\right) L}{\sigma\left(\bar{\pi}_{2}+f_{2}\right)} \frac{b}{\rho \widetilde{\varphi}_{2}} .
\end{aligned}
$$

Average profitability in each market, $\bar{\pi}_{1}$ and $\bar{\pi}_{2}$, is unchanged, while average productivity, $\widetilde{\varphi}_{1}$ and $\widetilde{\varphi}_{2}$, has risen. Hence, the fall in the sunk cost of entry reduces the price indices, $P_{1}$ and $P_{2}$, and increases welfare per worker, $W$. 


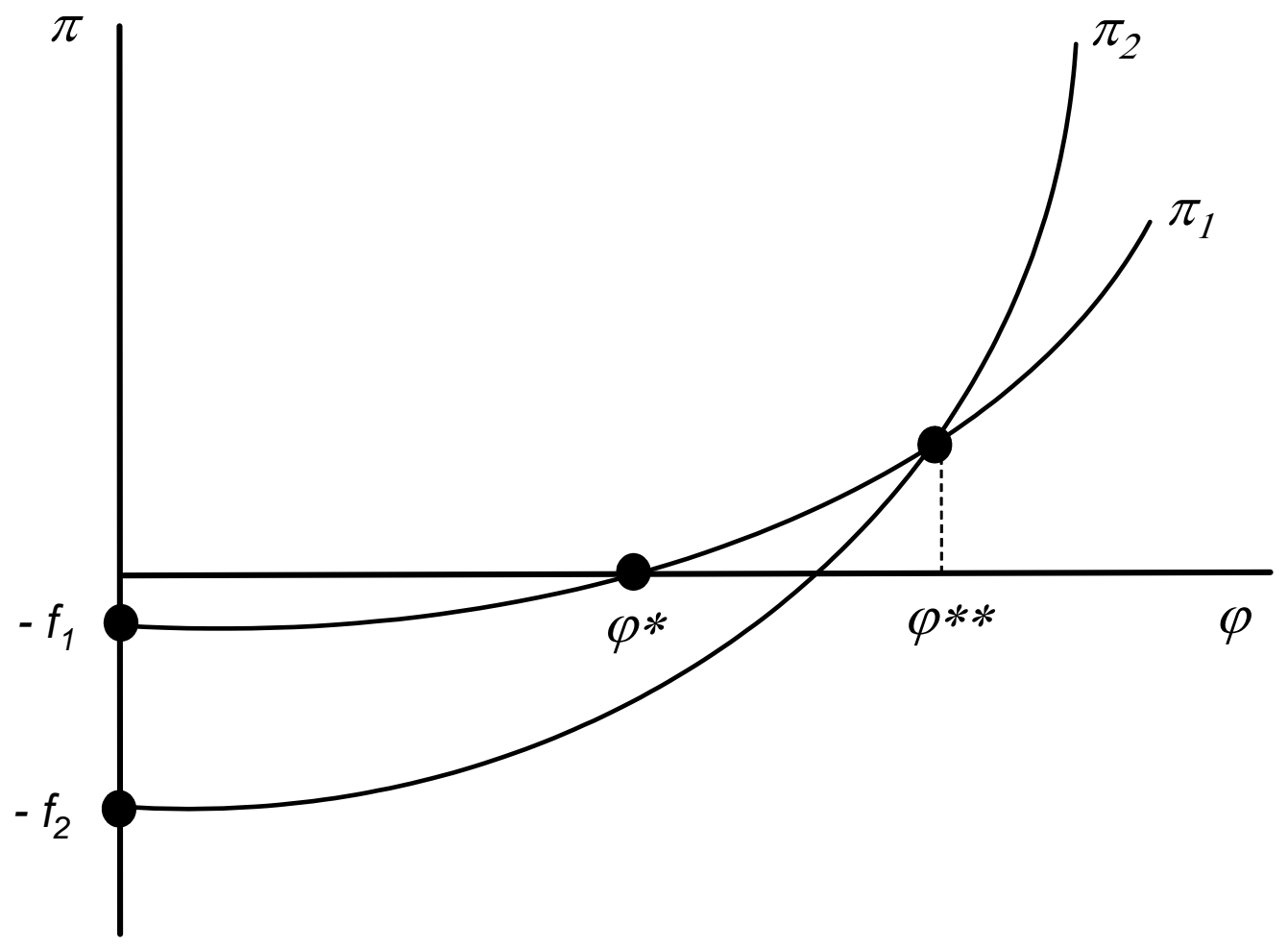

Figure 1: Profit versus Productivity for the Two Products 


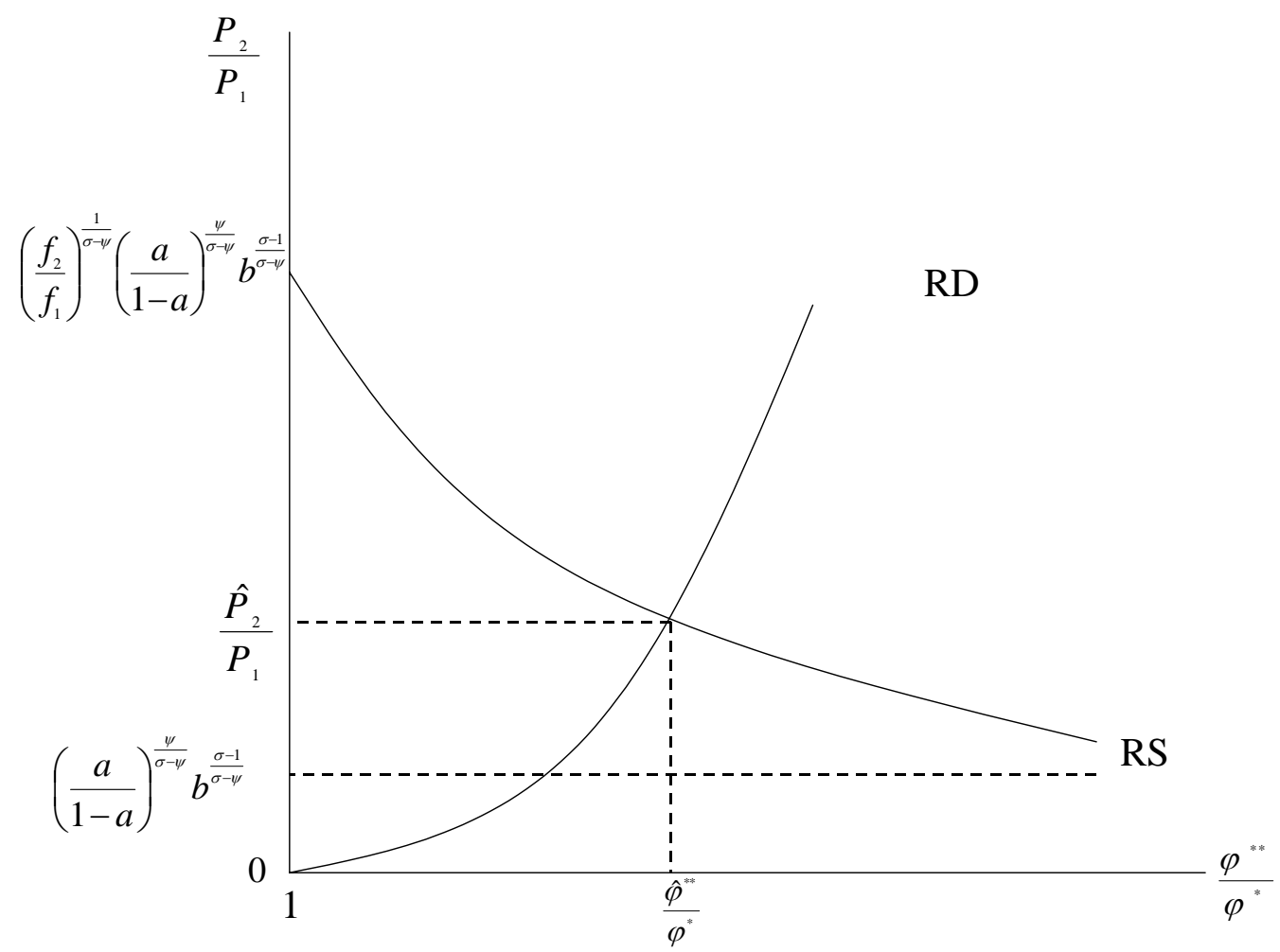

Figure 2: Equilibrium $\mathcal{P}$ and $\varphi^{* *} / \varphi^{*}$ 


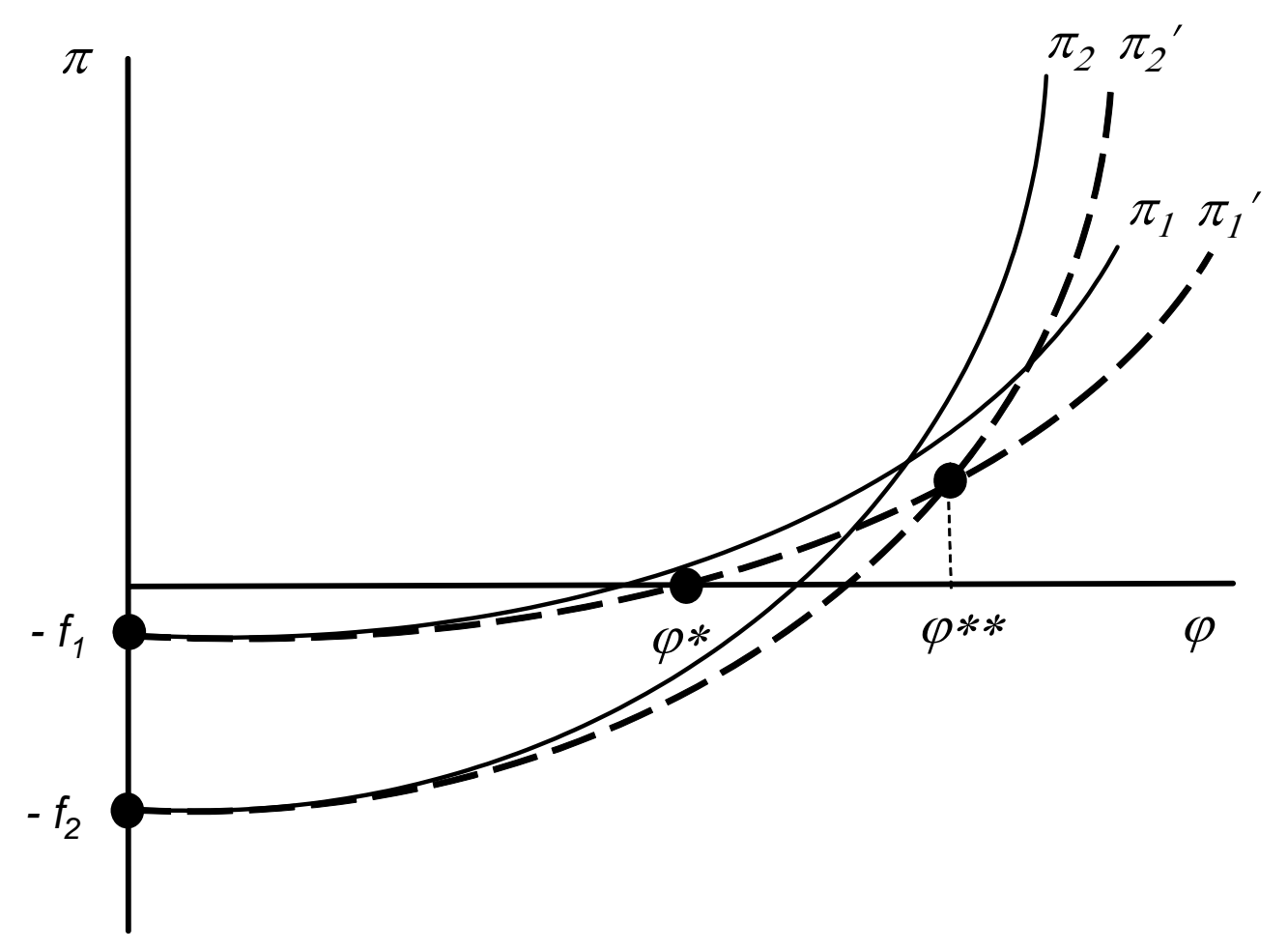

Figure 3: Comparative Statics with Respect to a Reduction in Barriers to Entry 


\begin{tabular}{lc:l} 
SIC & Description \\
\hline 33 & Primary Metal Industries \\
3357 & Nonferrous Wiredrawing and Insulating \\
33571 & Aluminum Wire \\
33572 & & Copper Wire \\
33573 & Pther Nonferrous Metal Wire \\
33575 & Nonferrous Wire Cloth \\
33576 & opparatus Wire and Cord Sets \\
33577 & o & Magnet Wire \\
33578 & d & Power Wire \\
3357A & u & Electronic Wire \\
3357B & c & Telephone Wire \\
3357C & t & Control Wire \\
3357D & s & Building Wire \\
3357E & Other Wire NES \\
33579 & Fiber Optic Cable \\
\hline Source: & U.S. Census Bureau (1996).
\end{tabular}

Table 1: Five-Digit SIC Products in Four-Digit SIC Industry 3357 (Nonferrous Wiredrawing and Insulating) 


\begin{tabular}{|c|c|c|c|}
\hline Two-Digit SIC Category & $\begin{array}{c}\text { SIC4 } \\
\text { Industries }\end{array}$ & $\begin{array}{c}\text { SIC5 } \\
\text { Products }\end{array}$ & $\begin{array}{l}\text { Products I } \\
\text { Industry }\end{array}$ \\
\hline 20 Food & 49 & 157 & 3.2 \\
\hline 21 Tobacco Products & 4 & 6 & 1.5 \\
\hline 22 Textile & 23 & 79 & 3.4 \\
\hline 23 Apparel & 31 & 75 & 2.4 \\
\hline 24 Lumber & 17 & 59 & 3.5 \\
\hline 25 Furniture & 13 & 36 & 2.8 \\
\hline 26 Paper & 17 & 55 & 3.2 \\
\hline 27 Printing and Publishing & 14 & 72 & 5.1 \\
\hline 28 Chemicals & 29 & 102 & 3.5 \\
\hline 29 Petroleum & 5 & 15 & 3.0 \\
\hline 30 Rubber and Plastics & 15 & 63 & 4.2 \\
\hline 31 Leather & 11 & 12 & 1.1 \\
\hline 32 Stone & 26 & 47 & 1.8 \\
\hline 33 Primary Metal & 26 & 89 & 3.4 \\
\hline 34 Fabricated Metal & 38 & 135 & 3.6 \\
\hline 35 Industrial Machinery & 51 & 187 & 3.7 \\
\hline 36 Electronic & 37 & 111 & 3.0 \\
\hline 37 Transportation & 18 & 65 & 3.6 \\
\hline 38 Instruments & 17 & 44 & 2.6 \\
\hline 39 Miscellaneous & 18 & 53 & 2.9 \\
\hline
\end{tabular}

Table 2: Products and Industries across Sectors 


$$
\begin{array}{ll}
d \varphi^{*}>0 & d \varphi^{* *}>0 \\
d\left(\varphi^{* *} / \varphi^{*}\right)=0 & d \mathcal{P}=0 \\
d \widetilde{\varphi}_{1}\left(\varphi^{*}, \varphi^{* *}\right)>0 & d \widetilde{\varphi}_{2}\left(\varphi^{* *}\right)>0 \\
d \bar{r}_{1}=0 & d \bar{r}_{2}=0 \\
d \bar{\pi}_{1}=0 & d \bar{\pi}_{2}=0 \\
d M_{1}=0 & d M_{2}=0 \\
d v_{e}<0 & d W>0
\end{array}
$$

Table 3: Comparative Statics with Respect to a Reduction in Barriers to Entry (a fall in sunk entry costs $f_{e}$ ) . 


\title{
CENTRE FOR ECONOMIC PERFORMANCE Recent Discussion Papers
}

\author{
698 Nicholas Oulton \\ Ex Post Versus Ex Ante Measures of the User Cost of \\ Capital \\ 697 Alan Manning \\ You Can't Always Get What You Want: the Impact \\ of the Jobseeker's Allowance \\ 696 Andrew B. Bernard \\ Stephen Redding \\ Peter K. Schott \\ Factor Price Equality and the Economies of the \\ United States \\ 695 Henry G. Overman \\ Anthony J. Venables \\ Cities in the Developing World \\ 694 Carlo Rosa \\ Giovanni Verga \\ The Importance of the Wording of the ECB \\ 693 Richard Dickens \\ Mirko Draca \\ The Employment Effects of the October 2003 \\ Increase in the National Minimum Wage \\ Computing the True Spread \\ 691 Augustin de Coulon \\ Immigrants at Retirement: Stay/Return or 'Va-et- \\ François-Charles Wolff \\ Vient'? \\ 690 Monika Merz \\ Labor and the Market Value of the Firm \\ 689 Pierre-Philippe Combes \\ Agglomeration and the Adjustment of the Spatial \\ Giles Duranton \\ Economy \\ Henry G. Overman \\ 688 Stephen Redding \\ Daniel M. Sturm \\ The Costs of Remoteness: Evidence from German \\ Division and Reunification \\ 687 Vicente Cuñat \\ Maria Guadalupe \\ How Does Product Market Competition Shape \\ Incentive Contracts? \\ 686 Maria Guadalupe \\ Product Market Competition, Returns to Skill and \\ Wage Inequality
}


685 Jo Blanden

Stephen Machin

John Van Reenen

684 Giovanna Vallanti

683 Gilles Duranton

Michael Storper

682 Carlo Rosa

Giovanni Verga

681 Nicholas Oulton

Sylaja Srinivasan

680 Stephen Machin

Olivier Marie

679 Alan Manning

Barbara Petrongolo

678 Andrew Clark

Fabien Postel-Vinay

677 Eran Yashiv

676 Alex Bryson

Rafael Gomez

Tobias Kretschmer

675 Nick Bloom

Mark Schankerman

John Van Reenen

674 Lorraine Dearden

Howard Reed

John Van Reenen
New Survey Evidence on Recent Changes in UK

Union Recognition

Capital Mobility and Unemployment Dynamics:

Evidence from a Panel of OECD Countries

Rising Trade Costs? Agglomeration and Trade with Endogenous Transaction Costs

Is ECB Communication Effective?

Productivity Growth and the Role of ICT in the

United Kingdom: An Industry View, 1970-2000

Crime and Police Resources: the Street Crime

Initiative

The Part-Time Pay Penalty

Job Security and Job Protection

Evaluating the Performance of the Search and Matching Model

Catching a Wave: the Adoption of Voice and High Commitment Workplace Practices in Britain: 19841998

Identifying Technology Spillovers and Product Market Rivalry

The Impact of Training on Productivity and Wages:

Evidence from British Panel Data

The Centre for Economic Performance Publications Unit Tel 02079557673 Fax $02079557595 \quad$ Email info@cep.lse.ac.uk Web site http://cep.Ise.ac.uk 